\title{
TD-DFT Calculations, NBO, NLO Analysis and Electronic Absorption Spectra of Some Novel Thiazolo[3,2-a]Pyridine Derivatives Bearing Anthracenyl Moiety
}

\author{
Shimaa Abdel Halim Hussien \\ Department of Chemistry, Faculty of Education, Ain Shams University, Cairo, Egypt \\ Email address: \\ Shimaaquantum@ymail.com \\ To cite this article: \\ Shimaa Abdel Halim Hussien. TD-DFT Calculations, NBO, NLO Analysis and Electronic Absorption Spectra of Some Novel Thiazolo[3,2- \\ a]Pyridine Derivatives Bearing Anthracenyl Moiety. International Journal of Computational and Theoretical Chemistry. \\ Vol. 7, No. 1, 2019, pp. 65-86. doi: 10.11648/j.ijctc.20190701.19
}

Received: January 28, 2019; Accepted: March 21, 2019; Published: May 17, 2019

\begin{abstract}
The electronic structure and spectra of the studied compounds 1-4 are investigated using TD-DFT/B3LYB/6$311 \mathrm{G}(\mathrm{d}, \mathrm{p})$ level of theory. The results of calculations show that all the studied compounds 1-4 are non-planar, as indicated from the dihedral angles. The electronic absorption spectra of the studied compounds are recorded in the UV-VIS region, in both Acetone (as polar solvent) and Xylene (as non-polar solvent). The observed vertical electronic transitions assignments are facilitated via time-dependent density functional theory TD-DFT. Solvent dependence of the band maxima $\left(\lambda_{\max }\right)$ and intensities of the observed spectra are explained in terms of blue and red shifts. Electronic configurations contributing to each excited state are identified and the relevant MOs are characterized. The natural bond orbital (NBO) analysis were discussed in terms of the extent of delocalization, intermolecular charge transfer and second order perturbation interactions between donor and acceptor MOs. The Coulomb-attenuating method (CAM-B3LYP) and Corrected Linear Response Polarizable Continuum Model (CLR) PCM studied for theoretically obtaining the electronic absorption spectra in gas phase, Acetone and Xylene, respectively, indicate a good agreement with the observed spectra. The calculated nonlinear optical parameters (NLO); polarizibilty $(\alpha)$, anisotropy of the polarizibility $(\Delta \alpha)$ and first order hyperpolarizibility $(\beta)$ of the studied compounds show promising optical properties. The HOMO-LUMO energy gap helped in analyzing the chemical reactivity, hardness, softness, chemical potential and electro negativity. 3D-plots of the molecular electrostatic potential (MEP) for the studied compounds are investigated and analyzed showing the distribution of electronic density of orbital's describing the electrophilic and nucleophilic sites of the selected molecules.
\end{abstract}

Keywords: UV Spectra, TD-DFT, Solvent and Substituent Effects, NBO and NLO Analysis

\section{Introduction}

The novel structure may be used in designing new potent and less toxic antimicrobial agents. Nitrogen-containing heterocyclic compounds have a diverse range of biological and pharmacological properties [1-4]. Thiazolo[3,2a]pyridines, containing two fused heterocyclic rings, also; it's found in medicinal chemistry as they have an excellent biological activity with a wide range of applications, including antimicrobial [5], antiviral [6] antihypertensive [7], antihistaminic [8], neurotropic [9], anticonvulsant [10], antidepressant, sedative, analgesic $[11,12]$ and anti-cancer activities. Among the various of anthraquinones are identified also biologically active compounds. A lot of anthraquinone compounds are found in plants, microorganisms [13], among of them are natural antibiotics anthracyclines [14] and cidamicines [15]. Recently, anthracene derivatives actively began to gain new application areas such as biologically active agents, analytical reagents [16-18], phosphors [19], the components of liquid crystal compositions, photo materials, chemical additives for polymeric materials and they have found their application in color photography and electrophotography, laser technology, LCD and photochromic materials [20, 21].

The newly synthesized thiazolo[3,2-a]Pyridines having anthranyl moiety derivatives $1-4$ are expected to have 
biological potential which needs to be explored by investigating their electronic structure and spectra experimentally and theoretically. The UV spectra, NLO and NBO analysis have been used to explain charge transfer within these molecules. The dependence on the electronic transitions to these molecules on the polarity of the solvent can be inferred from solvent-induced changes of such transitions, which is known as solvatochromism Corrected Linear Response Polarizable Continuum Model (CLR) PCM.

In continuation to our previous work [22-24], the objective of the present study aims to the calculations of density functional theory (DFT) and time-dependent density functional theory (TD-DFT) by using B3LYP at the 6$311 \mathrm{G}(\mathrm{d}, \mathrm{p})$ basis set to obtain geometries, electronic structures, non liner optical properties (NLO), natural bonding orbital's (NBO), UV-Vis spectra, and molecular electrostatic potential contours of the studied compounds $1-$ 4 , these parameters characterize the forces that govern the structure of the studied compounds $1-4$. The hybridization of each atom, natural charges, bonding and antibonding orbital's second order perturbation energy $(\mathrm{E}(2))$, exact configurations and Lewis and non-Lewis electrons results from natural bonding orbital analysis. The present work attempts to provide a detailed experimental (UV) and theoretical electronic structure and spectra of the studied compounds 14 using CAM- B3LYP/6-311G (d, p). The origin of each absorption band is identified and the contributing configurations and MOs are characterized. The identify the extent of delocalization and the charge transfer of the electron density in the studied molecular systems by Natural bond orbital analysis (NBO) and also; extent of conjugative interaction between different subsystems of the studied compounds. The effect of solvent polarity on the observed spectra and hence, predicting the relative stabilities, extent of charge transfers character and assignment of the observed electronic transitions are analyzed. The effect substituent's of different electron donating groups $(\mathrm{X}=\mathrm{CH} 3$ and $\mathrm{X}=\mathrm{OCH} 3)$ and electron withdrawing groups $(\mathrm{X}=\mathrm{Cl})$ on the electronic spectra of the studied compounds are discussed and analyzed. The molecular electrostatic potential (MEP) of the studied molecules were explored as well

\section{Experimental}

\subsection{Compounds}

The structure of the four proposed molecules 1-4 of Anthranyl Thiazolo[3,2-a]Pyridine derivatives, is shown below, where compound 1 is 5-amino-2 (anthracen-9ylmethylene)-3-oxo-7-phenyl-2,3-dihydro-7H-thiazolo[3,2a]pyridine-6,8 dicarbonitrile, compound 2 is 5-amino-2(anthracen-9-ylmethylene)-3-oxo-7-(p-tolyl) 2,3-dihydro-7Hthiazolo[3,2-a]pyridine-6,8-dicarbonitrile, compound 3 is 5 amino-2 (anthracen-9-ylmethylene)-7-(4-methoxyphenyl)-3oxo-2,3-dihydro-7H-thiazolo[3,2 a]pyridine-6,8dicarbonitrile, and compound 4 is 5-amino-2-(anthracen-9ylmethylene) 7-(4-chlorophenyl)-3-oxo-2,3-dihydro-7H- thiazolo[3,2-a]pyridine-6,8-dicarbonitrile.

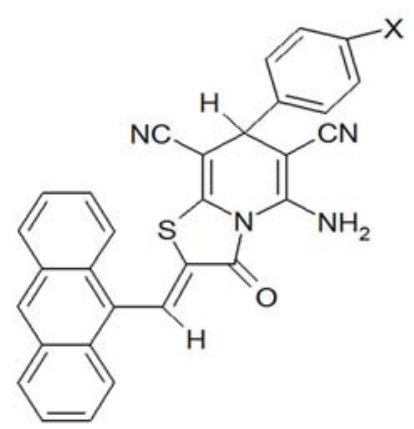

Figure 1. The structure of the four proposed molecules 1-4 of Anthranyl Thiazolo[3,2-a]Pyridine derivatives.

Table 1. The structure of the four proposed molecules 1-4 of Anthranyl Thiazolo[3,2-a]Pyridine derivatives.

\begin{tabular}{ll}
\hline Compounds & $\mathbf{X}$ \\
\hline 1 & $\mathrm{H}$ \\
2 & $\mathrm{CH}_{3}$ \\
3 & $\mathrm{OCH}_{3}$ \\
4 & $\mathrm{Cl}$ \\
\hline
\end{tabular}

\subsection{Solvents}

Polar (acetone) and non-polar (xylene) solvents were obtained from Merck, AR- grade, and were used without further purification.

\subsection{Apparatus}

A Perkin Elmer lambda 4B spectrophotometer using 1.0 $\mathrm{cm}$ fused quartz cells were used to measured the electronic absorption spectra over the range 200-900 $\mathrm{nm}$.

\subsection{Computational Details}

All computations were carried out using Khon-Sham's DFT method subjected to the gradient-corrected hybrid density functional B3LYP method [25]. This function is a combination of the Becke's three parameters non-local exchange potential with the non-local correlation functional of Lee et al [26]. For each structure, a full geometry optimization was performed using this function [26] and the 6-311G (d, p) bases set [27] as implemented by Gaussian 09 package [28]. All geometries were visualized either using GaussView 5.0.9 [29] or chemcraft 1.6 [30] software packages. No symmetry constrains were applied during the geometry optimization. Also, the total static dipole moment $(\mu),\langle\Delta \alpha\rangle$, and $\langle\beta\rangle$, values were calculated by using the following equations [31-33]:

$$
\begin{gathered}
\mu=\left(\mu_{x}^{2}+\mu_{y}^{2}+\mu_{z}^{2}\right)^{1 / 2}, \\
\langle\alpha\rangle=1 / 3\left(\alpha_{x x}+\alpha_{y y}+\alpha_{z z}\right), \\
\Delta \alpha=\left(\left(\alpha_{x x}-\alpha_{y y}\right)^{2}+\left(\alpha_{y y}-\alpha_{z z}\right)^{2}+\left(\alpha_{z z}-\alpha_{x x}\right)^{2} / 2\right)^{1 / 2}, \\
\langle\beta\rangle=\left(\beta_{x}^{2}+\beta_{y}^{2}+\beta_{z}^{2}\right)^{1 / 2}
\end{gathered}
$$

Where 


$$
\begin{aligned}
& \beta_{x}=\beta_{x x x}+\beta_{x y y}+\beta_{x z z}, \\
& \beta_{y}=\beta_{y y y}+\beta_{x x y}+\beta_{y z z}, \\
& \beta_{z}=\beta_{z z z}+\beta_{x x z}+\beta_{y y z} .
\end{aligned}
$$

The electronic transition properties which include the maximum excitation wavelength $\left(\lambda_{\max }\right)$ and relative intensities (oscillator strengths, $f$ ), were obtained by the time dependant density functional theory (TD-DFT), [34] using "A new hybrid exchange-correlation functional using the Coulomb-attenuating method (CAM-B3LYP)," at the 6-311G $(d, p)$ bases set [35]. The population analysis has also been performed by the natural bond orbital method [36] at B3LYP/6-311G (d, p) level of theory using natural bond orbital (NBO) under Gaussian 09 program package. The second-order Fock matrix was used to evaluate the donoracceptor interactions in the NBO basis [37]. For each donor $(i)$ and acceptor $(j)$, the stabilization energy $\mathrm{E}^{(2)}$ associated with the delocalization $i \rightarrow j$ is estimated as

$$
\text { (2) }=\Delta E_{i \mathrm{j}}=q_{i}\left(F(i \mathrm{j})^{2} / \varepsilon_{j}-\varepsilon_{i}\right),
$$

Where $q_{i}$ is the donor orbital occupancy, $\varepsilon_{i}$ and $\varepsilon_{j}$ are diagonal elements and $(i \mathrm{j})$ is the off-diagonal NBO Fock matrix element. For the conversion factors of $\alpha, \beta$, and HOMO and LUMO energies in atomic and cgs units: 1 atomic unit (a.u.) $=0.1482 \times 10^{-24}$ electrostatic unit (esu) for polarizability $\langle\alpha\rangle ; 1$ a.u. $=8.6393 \times 10^{-33}$ esu for first hyperpolarizability $\langle\beta\rangle ; 1$ a.u. $=27.2116 \mathrm{eV}$ for $\mathrm{HOMO}$ and LUMO energies.

\section{Result and Discussion}

\subsection{Electronic Structure}

\subsubsection{Geometry Structure}

'Figures 2-4, presents the optimized structures of the studied compounds 1-4, numbering system, HOMO and LUMO-charge density maps and the vector of dipole moment using the B3LYB/6-311G (d, p). From "Figures 2-4, it is obvious that, the optimized structures of the studied compounds, 1-4, is non-planer with the phenyl ring at $\mathrm{C}_{3}$ and anthranyl moiety at $\mathrm{C}_{9}$ are out of the molecular plane of novel thiazolo[3,2-a]Pyridines having anthranyl moiety by a dihedral angles of $111^{\circ}$ and $128^{\circ}$ respectively. The insertion of $\mathrm{X}=\mathrm{p}-\mathrm{Cl}, \mathrm{p}-\mathrm{CH} 3$, and $\mathrm{p}-\mathrm{OCH} 3$ at $\mathrm{C}_{3}$-ph does not change the geometry of the studied compounds 1-4 "Figure 2". This may be attributed to that the phenyl at $\mathrm{C}_{3}$ and anthranyl moiety at $\mathrm{C}_{9}$ are out of the molecular plane.

The optimized geometric parameters (bond lengths, bond angles and dihedral angles) of the parent molecule 1 and some of its derivatives 2-4 using B3LYP/6-311G (d,p) method are listed in Tables 2 and 3. The optimized bond lengths and bond angles are compared with the available $\mathrm{X}$ ray experimental data [38-40]. The observed bond lengths of $\mathrm{C}_{1}-\mathrm{C}_{2}$ and $\mathrm{C}_{2}-\mathrm{C}_{3}$ in pyridine ring are $1.371 \AA$ and $1.521 \AA$ respectively, while the theoretical values are $1.370 \AA$ and $1.518 \AA$ respectively. For $\mathrm{C}-\mathrm{S}$ bonds $\left(\mathrm{C}_{5}-\mathrm{S}_{8}\right.$ and $\left.\mathrm{S}_{8}-\mathrm{C}_{9}\right)$, the calculated values are greater than the experimental values by $0.045 \AA$ and $0.014 \AA$ respectively. There is a great agreement between the calculated bond lengths of the parent 1 and the experimental values indicating the power of the method used. For derivative 2 , the calculated bond angles $<\mathrm{C} 4 \mathrm{C} 5 \mathrm{~S} 8$ $\left(124.85^{\circ}\right)$ and $<\mathrm{N} 6 \mathrm{C} 10 \mathrm{C} 9\left(110.24^{\circ}\right)$ are overestimated than the experimental values, whereas, the calculated bond angles $<\mathrm{C} 5 \mathrm{~N} 6 \mathrm{C} 1 \quad\left(119.23^{\circ}\right)$ and $<\mathrm{N} 6 \mathrm{C} 5 \mathrm{~S} 8 \quad\left(111.86^{\circ}\right)$ are underestimated than the experimental values (c.f. Table 2). The effect of different substituent's in the derivatives 3 and 4 are listed in Table 2. There are disagreement between the calculated bond angle and the experimental values which may be attributed to that the calculation were carried out in the gas phase and the experimental measured in the solid state. All the studied compounds 2a-d are non-planner as

\begin{tabular}{|c|c|c|c|c|c|}
\hline Parameters & EXP.[38-40] & 1 & 2 & 3 & 4 \\
\hline \multicolumn{6}{|c|}{ Bond lengths $(\AA)$} \\
\hline $\mathrm{C}_{1}-\mathrm{C}_{2}$ & 1.371 & 1.370 & 1.370 & 1.370 & 1.370 \\
\hline $\mathrm{C}_{2}-\mathrm{C}_{3}$ & 1.521 & 1.518 & 1.518 & 1.518 & 1.517 \\
\hline $\mathrm{C}_{4}-\mathrm{C}_{5}$ & 1.341 & 1.349 & 1.349 & 1.349 & 1.349 \\
\hline $\mathrm{C}_{5}-\mathrm{N}_{6}$ & 1.389 & 1.402 & 1.402 & 1.402 & 1.402 \\
\hline $\mathrm{C}_{1}-\mathrm{N}_{6}$ & 1.387 & 1.420 & 1.420 & 1.420 & 1.420 \\
\hline $\mathrm{C}_{5}-\mathrm{S}_{8}$ & 1.722 & 1.767 & 1.767 & 1.768 & 1.766 \\
\hline $\mathrm{S}_{8}-\mathrm{C}_{9}$ & 1.753 & 1.767 & 1.767 & 1.767 & 1.768 \\
\hline $\mathrm{C}_{9}-\mathrm{C}_{10}$ & 1.399 & 1.481 & 1.481 & 1.482 & 1.480 \\
\hline $\mathrm{C}_{9}-\mathrm{C}_{11}$ & 1.341 & 1.346 & 1.346 & 1.346 & 1.347 \\
\hline $\mathrm{C}_{11}-\mathrm{C}_{31}$ & 1.451 & 1.468 & 1.468 & 1.468 & 1.467 \\
\hline $\mathrm{C}_{10^{-}}-\mathrm{N}_{6}$ & 1.412 & 1.406 & 1.406 & 1.405 & 1.407 \\
\hline $\mathrm{C}_{10}-\mathrm{O}_{23}$ & 1.290 & 1.217 & 1.217 & 1.217 & 1.217 \\
\hline $\mathrm{C}_{1}-\mathrm{N}_{24}$ & 1.345 & 1.354 & 1.355 & 1.356 & 1.354 \\
\hline $\mathrm{C}_{2}-\mathrm{C}_{27}$ & 1.389 & 1.414 & 1.414 & 1.414 & 1.414 \\
\hline $\mathrm{C}_{27}-\mathrm{N}_{29}$ & 1.190 & 1.159 & 1.159 & 1.159 & 1.159 \\
\hline $\mathrm{C}_{3}-\mathrm{C}_{13}$ & 1.524 & 1.533 & 1.532 & 1.531 & 1.533 \\
\hline
\end{tabular}
indicating from the calculated dihedral angles (c.f. Table 3).

Table 2. Selected experimental and theoretical bond lengths, and bond angles for the studied compounds (1-4) computed at the B3LYP/6-311G(d,P) level of theory. 
Shimaa Abdel Halim Hussien: TD-DFT Calculations, NBO, NLO Analysis and Electronic Absorption Spectra of Some Novel Thiazolo[3,2-a]Pyridine Derivatives Bearing Anthracenyl Moiety

\begin{tabular}{|c|c|c|c|c|c|}
\hline Parameters & EXP.[38-40] & 1 & 2 & 3 & 4 \\
\hline $\mathrm{C}_{4}-\mathrm{C}_{28}$ & 1.412 & 1.419 & 1.419 & 1.419 & 1.419 \\
\hline $\mathrm{C}_{28}-\mathrm{N}_{30}$ & 1.190 & 1.157 & 1.157 & 1.157 & 1.157 \\
\hline \multicolumn{6}{|c|}{ Bond Angles $\left(\left(^{0}\right)\right.$} \\
\hline$<\mathrm{N}_{6}-\mathrm{C}_{1}-\mathrm{C}_{2}$ & 120.00 & 119.31 & 119.29 & 119.31 & 119.31 \\
\hline$<\mathrm{C}_{1}-\mathrm{C}_{2}-\mathrm{C}_{3}$ & 124.99 & 124.89 & 124.87 & 124.91 & 124.81 \\
\hline$<\mathrm{C}_{2}-\mathrm{C}_{3}-\mathrm{C}_{4}$ & 109.31 & 109.82 & 109.75 & 109.71 & 109.82 \\
\hline$<\mathrm{C}_{3}-\mathrm{C}_{4}-\mathrm{C}_{5}$ & 121.00 & 122.28 & 122.26 & 122.28 & 122.20 \\
\hline$<\mathrm{C}_{4}-\mathrm{C}_{5}-\mathrm{S}_{8}$ & 123.99 & 124.85 & 124.90 & 124.93 & 124.86 \\
\hline$<\mathrm{C}_{4}-\mathrm{C}_{5}-\mathrm{N}_{6}$ & 123.95 & 123.29 & 123.26 & 123.26 & 123.26 \\
\hline$<\mathrm{C}_{5}-\mathrm{N}_{6}-\mathrm{C}_{1}$ & 119.80 & 119.23 & 119.22 & 119.20 & 119.25 \\
\hline$<\mathrm{N}_{6}-\mathrm{C}_{5}-\mathrm{S}_{8}$ & 110.96 & 111.86 & 111.84 & 111.81 & 111.88 \\
\hline$<\mathrm{N}_{6}-\mathrm{C}_{10}-\mathrm{C}_{9}$ & 109.55 & 110.24 & 110.26 & 110.27 & 110.25 \\
\hline$<\mathrm{S}_{8}-\mathrm{C}_{9}-\mathrm{C}_{10}$ & 110.69 & 111.39 & 111.37 & 111.36 & 111.38 \\
\hline$<\mathrm{C}_{9}-\mathrm{S}_{8}-\mathrm{C}_{5}$ & 95.411 & 91.102 & 91.102 & 91.110 & 91.107 \\
\hline$<\mathrm{C}_{11}-\mathrm{C}_{9}-\mathrm{S}_{8}$ & 130.81 & 127.94 & 127.98 & 128.10 & 128.03 \\
\hline$<\mathrm{C}_{9}-\mathrm{C}_{11}-\mathrm{C}_{31}$ & 127.99 & 128.40 & 128.45 & 128.67 & 128.67 \\
\hline$<\mathrm{C}_{9}-\mathrm{C}_{10}-\mathrm{O}_{23}$ & 124.61 & 124.82 & 124.81 & 124.79 & 124.92 \\
\hline$<\mathrm{O}_{23}-\mathrm{C}_{10}-\mathrm{N}_{6}$ & 125.00 & 124.94 & 124.93 & 124.94 & 124.83 \\
\hline$<\mathrm{C}_{10}-\mathrm{N}_{6}-\mathrm{C}_{1}$ & 125.00 & 125.36 & 125.36 & 125.36 & 125.34 \\
\hline$<\mathrm{N}_{6}-\mathrm{C}_{1}-\mathrm{N}_{24}$ & 115.92 & 116.23 & 116.23 & 116.22 & 116.31 \\
\hline$<\mathrm{N}_{24}-\mathrm{C}_{1}-\mathrm{C}_{2}$ & 125.00 & 124.39 & 124.40 & 124.40 & 124.32 \\
\hline$<\mathrm{C}_{1}-\mathrm{C}_{2}-\mathrm{C}_{27}$ & 116.95 & 117.11 & 117.11 & 117.06 & 117.18 \\
\hline$<\mathrm{C}_{2}-\mathrm{C}_{27}-\mathrm{N}_{29}$ & 177.99 & 178.15 & 178.16 & 178.10 & 178.28 \\
\hline$<\mathrm{C}_{2}-\mathrm{C}_{3}-\mathrm{C}_{13}$ & 113.69 & 112.10 & 112.10 & 113.18 & 113.06 \\
\hline$<\mathrm{C}_{4}-\mathrm{C}_{3}-\mathrm{C}_{13}$ & 113.36 & 111.25 & 111.28 & 111.30 & 111.06 \\
\hline$<\mathrm{C}_{3}-\mathrm{C}_{4}-\mathrm{C}_{28}$ & 117.96 & 118.27 & 118.26 & 118.27 & 118.22 \\
\hline$<\mathrm{C}_{4}-\mathrm{C}_{28}-\mathrm{N}_{30}$ & 177.99 & 179.17 & 179.15 & 179.14 & 179.05 \\
\hline
\end{tabular}

Table 3. Dihedral Angles $\left({ }^{\circ}\right)$ and Natural Charge for the studied compounds (1-4) computed at the B3LYP/6-311G(d,P) level of theory.

\begin{tabular}{|c|c|c|c|c|}
\hline Parameters & 1 & 2 & 3 & 4 \\
\hline \multicolumn{5}{|c|}{ Dihedral Angles $\left({ }^{\circ}\right)$} \\
\hline$<\mathrm{C}_{1} \mathrm{C}_{2} \mathrm{C}_{3} \mathrm{C}_{4}$ & 9.324 & 10.094 & 10.031 & 10.150 \\
\hline$<\mathrm{C}_{3} \mathrm{C}_{4} \mathrm{C}_{5} \mathrm{~N}_{6}$ & 3.255 & 3.534 & 3.712 & 3.641 \\
\hline$<\mathrm{C}_{4} \mathrm{C}_{5} \mathrm{~N}_{6} \mathrm{C}_{1}$ & 6.323 & 6.669 & 6.572 & 6.640 \\
\hline$<\mathrm{C}_{4} \mathrm{C}_{5} \mathrm{~S}_{8} \mathrm{C}_{9}$ & 177.72 & 177.44 & 177.24 & 177.55 \\
\hline$<\mathrm{N}_{6} \mathrm{C}_{5} \mathrm{~S}_{8} \mathrm{C}_{9}$ & -1.474 & -1.670 & -1.834 & -1.612 \\
\hline$<\mathrm{S}_{8} \mathrm{C}_{9} \mathrm{C}_{11} \mathrm{C}_{31}$ & 1.044 & 0.969 & 0.972 & 1.130 \\
\hline$<\mathrm{S}_{8} \mathrm{C}_{9} \mathrm{C}_{10} \mathrm{~N}_{6}$ & 1.538 & 1.511 & 1.150 & 1.058 \\
\hline$<\mathrm{O}_{23} \mathrm{C}_{10} \mathrm{~N}_{6} \mathrm{C}_{1}$ & -5.148 & -5.266 & -5.059 & -5.225 \\
\hline$<\mathrm{C}_{10} \mathrm{~N}_{6} \mathrm{C}_{1} \mathrm{~N}_{24}$ & -7.091 & -7.518 & -7.634 & -6.924 \\
\hline$<\mathrm{N}_{6} \mathrm{C}_{1} \mathrm{~N}_{24} \mathrm{H}_{25}$ & 173.43 & 173.10 & 173.11 & 173.73 \\
\hline$<\mathrm{C}_{1} \mathrm{C}_{2} \mathrm{C}_{27} \mathrm{~N}_{29}$ & -9.194 & -9.633 & -7.939 & -8.454 \\
\hline$<\mathrm{C}_{3} \mathrm{C}_{4} \mathrm{C}_{28} \mathrm{~N}_{30}$ & -54.427 & -55.646 & -57.167 & -42.223 \\
\hline$<\mathrm{C}_{13} \mathrm{C}_{3} \mathrm{C}_{4} \mathrm{C}_{28}$ & -63.119 & -63.658 & -63.350 & -63.796 \\
\hline$<\mathrm{C}_{13} \mathrm{C}_{3} \mathrm{C}_{2} \mathrm{H}_{7}$ & 118.034 & 118.088 & 118.095 & 118.128 \\
\hline$<\mathrm{C}_{9} \mathrm{C}_{11} \mathrm{C}_{31} \mathrm{H}_{12}$ & -175.43 & -175.40 & -175.40 & -175.41 \\
\hline \multicolumn{5}{|l|}{ Natural Charge } \\
\hline $\mathrm{C} 1$ & 0.4622 & 0.4615 & 0.4598 & 0.4633 \\
\hline $\mathrm{C} 2$ & -0.2796 & -0.2794 & -0.2778 & -0.2838 \\
\hline N6 & -0.4702 & -0.4701 & -0.4691 & -0.4705 \\
\hline S8 & 0.4004 & 0.3998 & 0.3987 & 0.4024 \\
\hline C9 & -0.2673 & -0.2668 & -0.2675 & -0.2689 \\
\hline $\mathrm{C} 10$ & 0.6842 & 0.6851 & 0.6839 & 0.6851 \\
\hline $\mathrm{O} 23$ & -0.6064 & -0.6077 & -0.6077 & -0.6063 \\
\hline N24 & -0.7677 & -0.7678 & -0.7696 & -0.7661 \\
\hline N29 & -0.3461 & -0.3436 & -0.3446 & -0.3420 \\
\hline N30 & -0.3037 & -0.2990 & -0.3008 & -0.2960 \\
\hline C55 & -------- & -0.5835 & -0.1977 & --------- \\
\hline O54 & --------- & -------- & -0.5216 & -------- \\
\hline $\mathrm{Cl} 54$ & ------- & ------- & --------- & -0.0070 \\
\hline
\end{tabular}




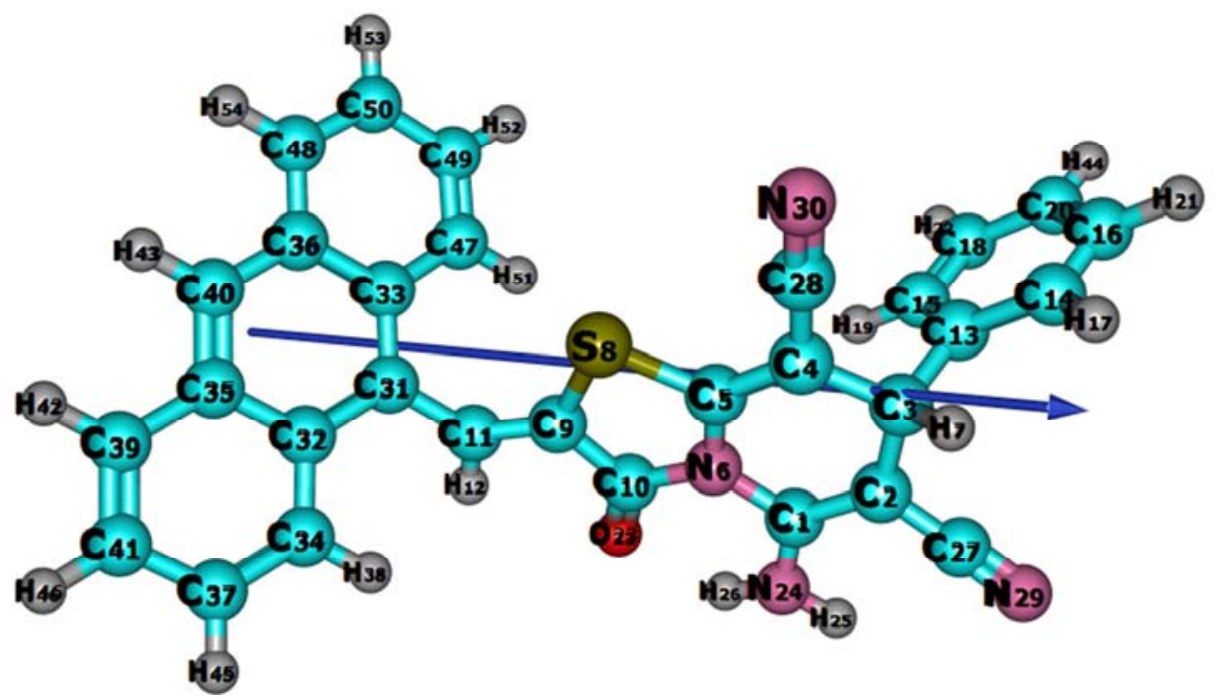

(1)

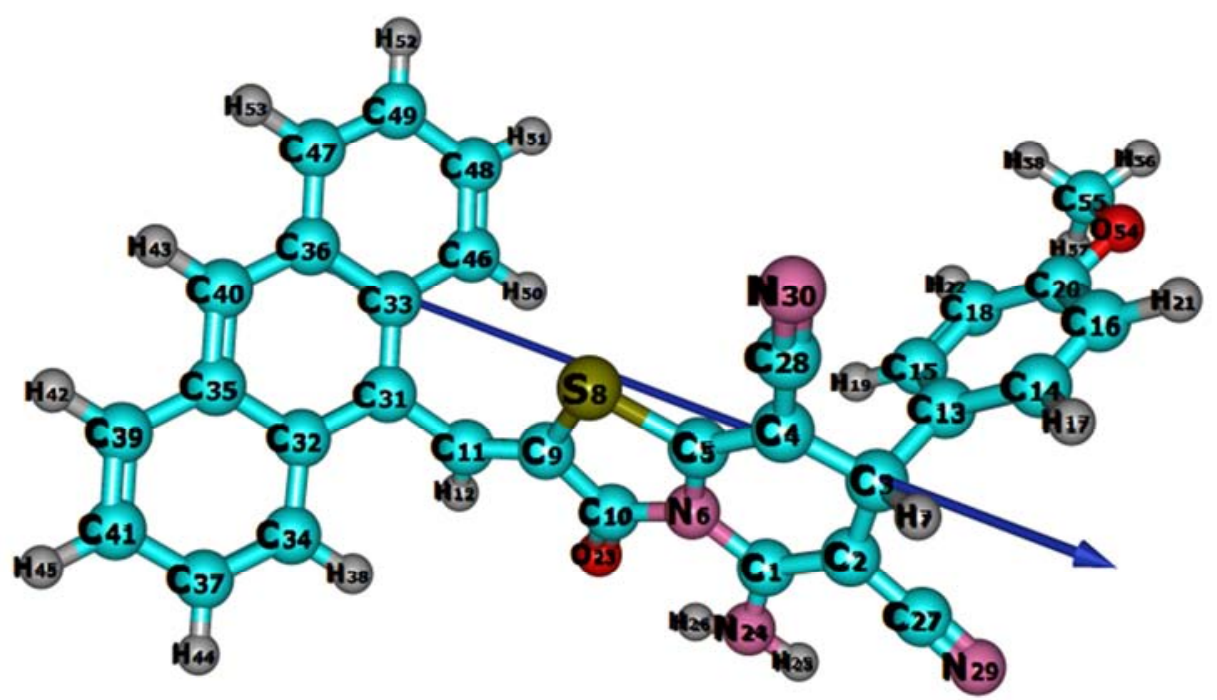

(2)

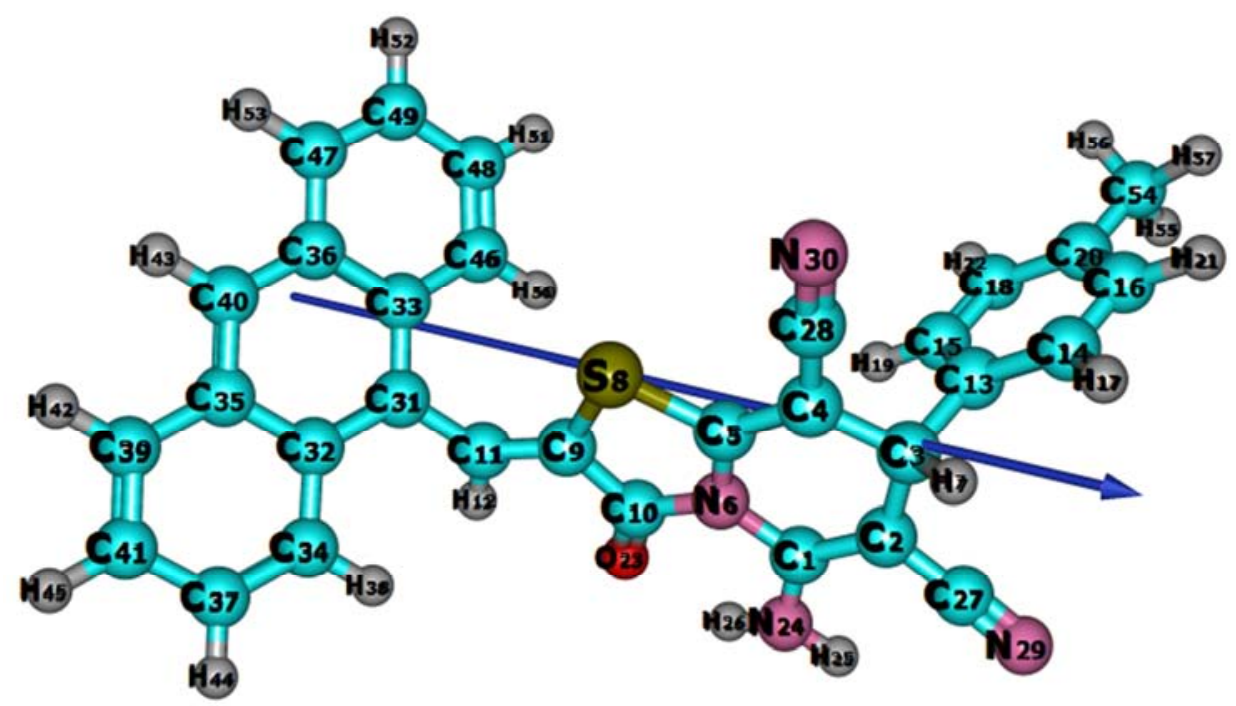

(3) 


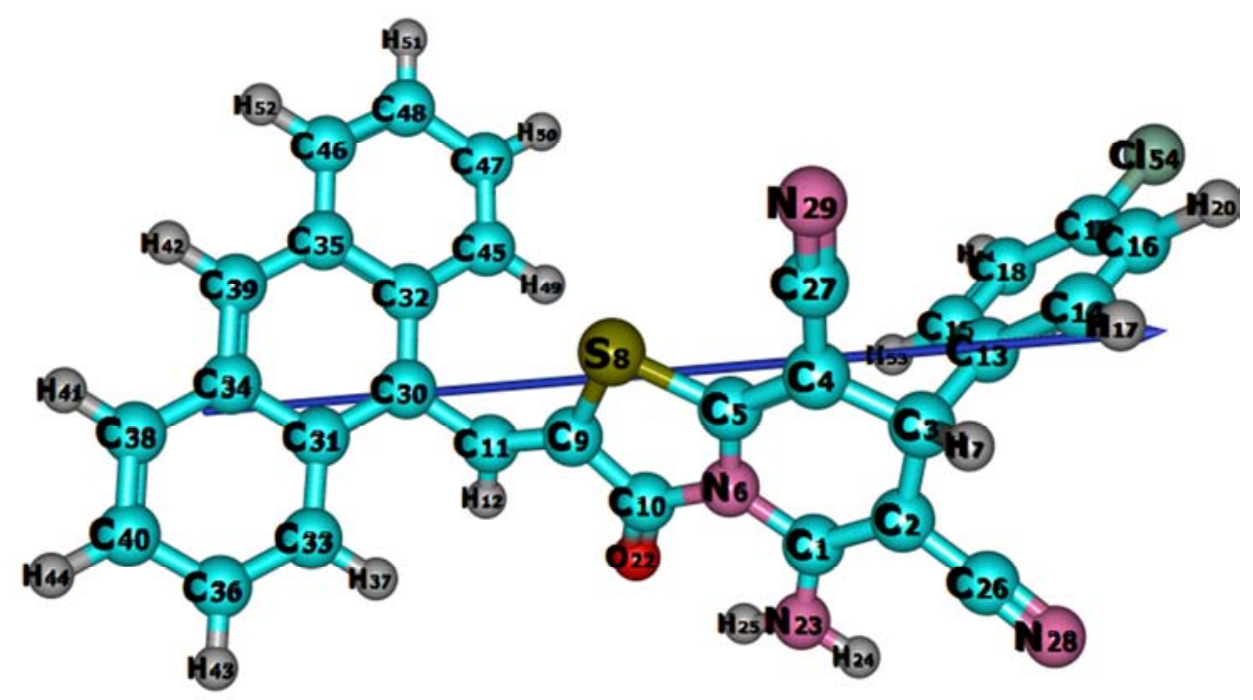

(4)

Figure 2. Optimized geometry, vector of the dipole moment and numbering system, for the studied compounds 1-4 at B3LYP/6-311G (d, p).

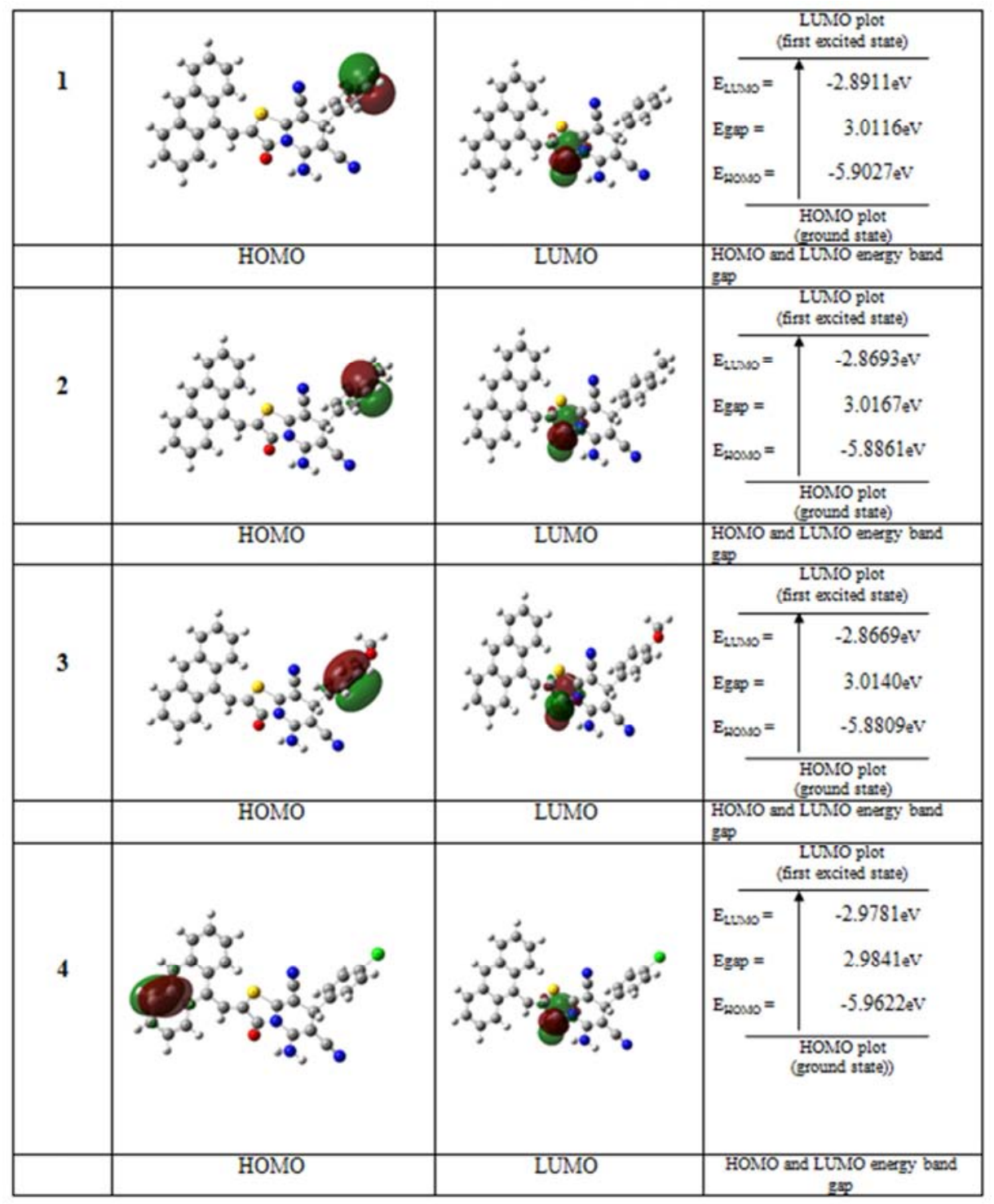

Figure 3. HOMO, LUMO maps and energy gap of 1-4 at B3LYP/6-311G (d, p). 


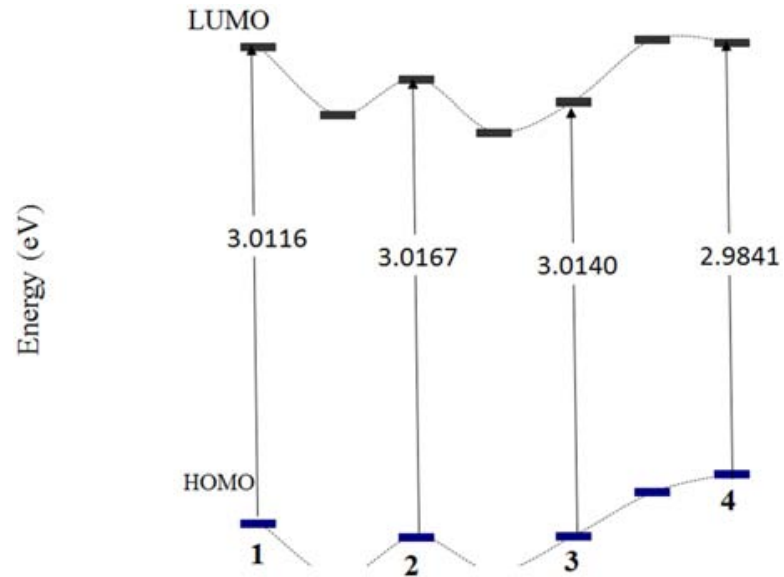

Figure 4. Energy of HOMO, LUMO and energy gap of the studied compounds 1-4 at B3LYP/6-311G (d, p) level of theory.

\subsubsection{Ground State Properties}

The ionization energy, I. E, of compound 1 which measures the donating property (oxidation power) is $5.90 \mathrm{eV}$ (c.f. Table 4). The effect of substituent's of different strengths and hence in the donating properties follows the order: $3>$ $2>1>4$, as shown in Table 4 and "Figures 3 and 4". However the electron affinity, E. A., of 1 which measures the accepting property (reducing power) is $2.89 \mathrm{eV}$. The order of accepting properties of novel thiazolo[3,2-a]Pyridines having anthranyl moiety derivatives follows $3<2<1<4$, as shown in Table 4 and "Figure 4". The band gap, $E_{\text {gap }}$, is the energy gap between $\mathrm{E}_{\mathrm{HOMO}}$ and $\mathrm{E}_{\mathrm{LUMO}}$, it signifies the facile electron transition from $\mathrm{E}_{\mathrm{HOMO}}$ to $\mathrm{E}_{\mathrm{LUMO}}$, i.e. the reactivity of molecules in the studied compounds 1-4 are governed by their chemical structures. The results in Table 4 and "Figure $4 "$, shows that the computed reactivity in the gas phase of the studied compounds increases in the order: $4>1>3>2$. This indicates that the smaller the $\mathrm{E}_{\text {gap }}$, the higher the reactivity of these compounds. The derivatives 2 and 3 , the calculated $\mathrm{E}_{\text {gap }}$ are greater (less reactive) than the parent 1 by about $\approx 0.2$ and $0.06 \mathrm{kcal} / \mathrm{mol}$ respectively, while the derivative 4 , the computed $\mathrm{E}_{\text {gap }}$ are lower (high reactive) than the parent $2 \mathrm{a}$ by $0.027 \mathrm{eV}(\approx 0.63 \mathrm{kcal} / \mathrm{mol})$. Therefore, all functions must be attached to the fused thiazolo[3,2-a]pyridine the parent molecule leading to its reactivity. Finally, the theoretically computed dipole moment, $\mu$, for compound 1 which measures the charge separation over the molecule is $6.62 \mathrm{D}$. The general trend of the dipole moment changes for the studied compounds 1-4 follow the order $4>3>1>2$ (c.f. Table 4) and the vector of the dipole moment is presented in "Figure 2". From the computed dipole moment, it's found that the presence of two cyano groups at $\mathrm{C}_{2}$ and $\mathrm{C}_{4}$ and anthracene group at $\mathrm{C}_{9}$ (c.f. "Figures 2 and $3 "$ ) are responsible for the polarity of the compound 1 (c.f. Table 2).

Table 4. Total energy, energy of HOMO and LUMO, energy gap, dipole moment, The ionization potential (I leV), electron affinity (A leV), chemical hardness $(\eta / \mathrm{eV})$, global softness $\left(\mathrm{S} / \mathrm{eV}^{-1}\right)$, chemical potential $\left(\mathrm{V} / \mathrm{eV}^{-1}\right)$, electronegativity $(\chi / \mathrm{eV})$, and global electrophilicity index, $(\omega / \mathrm{eV})$, of the studied compounds $(1-$ 4) computed at the $B 3 L Y P / 6-311 G(d, P)$.

\begin{tabular}{|c|c|c|c|c|}
\hline Compounds & 1 & 2 & 3 & 4 \\
\hline $\mathrm{E}_{\mathrm{T}}(\mathrm{au})$ & -1846.7984 & -1886.1263 & -1961.3519 & -2306.4198 \\
\hline $\mathrm{E}_{\text {номо }}(\mathrm{eV})$ & -5.90267 & -5.88608 & -5.88091 & -5.96224 \\
\hline$E_{\text {LUMO }}(\mathrm{eV})$ & -2.89109 & -2.86933 & -2.86688 & -2.97813 \\
\hline $\mathrm{E}_{\text {gap }}(\mathrm{eV})$ & 3.01158 & 3.01675 & 3.01403 & 2.98411 \\
\hline$\mu$ (Debye) & 6.6222 & 6.3840 & 7.2805 & 8.0169 \\
\hline$I(e V)$ & 5.90267 & 5.88608 & 5.88091 & 5.96224 \\
\hline$X(e V)$ & 4.39688 & 4.37770 & 4.37389 & 4.47018 \\
\hline$V\left(e V^{-1}\right)$ & -4.39688 & -4.37770 & -4.37389 & -4.47018 \\
\hline$\eta(e V)$ & 1.50579 & 1.50837 & 1.50701 & 1.49206 \\
\hline$S\left(e V^{1}\right)$ & 0.33205 & 0.33148 & 0.33178 & 0.33511 \\
\hline$\omega(\mathrm{eV})$ & 6.41940 & 6.35261 & 6.34729 & 6.69630 \\
\hline
\end{tabular}

\subsubsection{Natural Charge}

The natural population analysis [41] performed on the electronic structures of compounds 1-4 clearly describes the distribution of electrons in various sub-shells of their atomic orbits. The accumulations of charges on the individual atom presented in Table 3. In case of our studied compounds 1-4, the most negative centers are N6, O23, N24, N29, N30, O54, and $\mathrm{Cl} 54$-atoms. According to an electrostatic point of view of the molecule, these negative atoms have a tendency to donate an electron. Whereas, the most electropositive atoms such as; S8 have a tendency to accept an electron. These distributions of partial charges on the skeletal atoms show that the electrostatic repulsion or attraction between atoms can give a significant contribution to the intra- and intermolecular interaction.

\subsection{Global Reactivity Descriptors}

They include HOMO, LUMO, energy gap $\left(\mathrm{E}_{\mathrm{g}}\right)$, chemical hardness $(\eta)$, electronegativity $(X)$, chemical potential $(V)$, electrophilicity $(\omega)$, electron affinity (A), ionization potential (I) and global softness $(S)$ which are calculated at B3LYP/6-311G (d,p). The frontier molecular orbital (FMO) energies of the studied compounds were calculated at the same level of theory. HOMO energy characterizes the electron donating ability, while LUMO energy characterizes the electron withdrawing ability. Energy gap $\left(E_{g}\right)$ between 
HOMO and LUMO characterizes the molecular chemical stability which is a critical parameter in determining molecular electrical transport properties because it is a measure of electron conductivity. The results in "Figure 3". and Table 4 indicate that the smaller the energy gap the easier the charge transfer and the polarization occurs within the molecule. Furthermore, the order of increasing reactivity in the studied compounds is: $4>1>3>2$. The insignificant differences in $\mathrm{E}_{\mathrm{g}}$ of all the studied compounds except 4 is due to the non-planarity of the two ph-X and anthracene group with the thiazolo[3,2-a]pyridine moiety (c.f. Table 4). Using HOMO and LUMO energies, ionization potential and electron affinity can be expressed as $\mathrm{I} \sim-\mathrm{E}_{\mathrm{HOMO}}, \mathrm{A} \sim-\mathrm{E}_{\mathrm{LUMO}}$ at the $\mathrm{B} 3 \mathrm{LYP} / 6-311 \mathrm{G}(\mathrm{d}, \mathrm{p})$ as shown in (Table 4). The variation of electronegativity $(X)$ values is supported by electrostatic potential, for any two molecules, where electron will be partially transferred from one of low $X$ to that of high $X$. The results show that the order of decreasing $X$ is: $4<1<2<3$. The chemical hardness $(\eta)=(\mathrm{I}-\mathrm{A}) / 2$, electronegativity $(X)=(\mathrm{I}+\mathrm{A}) / 2$, chemical potential $(\mathrm{V})=-(\mathrm{I}+\mathrm{A}) / 2$, electrophilicity $(\omega)=\mu^{2} /$ $2 \eta$ and global softness $(\mathrm{S})=1 / 2 \eta$ values are calculated and presented in Table 4 . The results of small $\eta$ values for the studied compounds reflect the ability of charge transfer inside the molecule. Therefore, the order is: $4>1>3>2$. There is a linear relationship between $\eta$ and $E_{g}$ as shown in (Table 4). Considering $\eta$ values, the higher the $\eta$ values, the harder is the molecule and vice versa.

\subsection{Nonlinear Optical (NLO) Analysis}

Non-linear optical properties are the ability of any compound to convert light of longer wave length into light of shorter wave length. Most applications of single crystals of any non linear materials are evident in the fields of semiconductors, infrared detectors, solid state lasers, photosensitive materials and crystalline thin films for microelectronics [42]. The investigation of the relationship between the electronic structure and NLO, parameters of the studied compounds 1-4 are calculated theoretically by using DFT/B3LYP/6-311G (d,p). Total static dipole moment $(\mu)$, the mean polarizibility $\alpha$, the anisotropy of the polarizability $\Delta \alpha$, the mean first-order hyperpolarizibility $(\beta)$ of the studied compounds 1-4 are listed in Table 5. In this study, P-nitro aniline (PNA) is a standard prototype molecule used in NLO studies, its chosen as a reference as there were no experimental values of NLO properties of the studied compounds. The values of $\alpha, \beta$ in Table 5 show that the order of increasing $\alpha$ with respect to PNA is: compounds 3 and 2 are $\sim 3.5$ and 3 times higher than (PNA), whereas compounds 4 and 1 are $\sim 3$ times higher than the standard (PNA) respectively, The calculated first order hyperpolarizability of p- nitroacetanilide (PNA) is $15.5 \times 10^{-30}$ esu as reported by $\mathrm{T}$. Gnanasambandan et al [43-45]. The analysis of the $\beta$ parameter show that compounds 1 and 3 are $\sim 2$ times higher than (PNA), while compounds 2 , and 4 are $\sim 1.5$ times higher than the reference respectively. Therefore, the studies compounds show promising optical properties.

Table 5. Total static dipol moment $(\mu)$, the mean polarizability $(\langle\alpha\rangle)$, the anisotropy of the polarizability $(\Delta \alpha)$, and the mean first-order hyperpolarizability $(<\beta>)$, for the studied compounds (1-4) computed at B3LYP/6-311 G(d,P).

\begin{tabular}{|c|c|c|c|c|c|}
\hline Property & PNA & 1 & 2 & 3 & 4 \\
\hline$\mu_{\mathrm{x}}, \mathrm{D}$ & & -2.3970 & -2.19358 & -2.25501 & -1.96204 \\
\hline$\mu_{\mathrm{y}}, \mathrm{D}$ & & 0.22663 & 0.53737 & 0.86366 & 0.32376 \\
\hline$\mu_{z}, D$ & & -0.98272 & -1.08832 & -1.53756 & -0.62330 \\
\hline$\mu$, Debye $^{a}$ & 2.44 & 2.60052 & 2.506992 & 2.862706 & 2.083967 \\
\hline$\alpha_{\mathrm{Xx}}$, a.u. & & 610.816 & 637.430 & 647.415 & 631.077 \\
\hline$\alpha_{X Y}$, a.u. & & 38.9403 & 37.7679 & 32.4371 & 37.9918 \\
\hline$\alpha_{Y Y}$, a.u. & & 424.426 & 436.336 & 439.636 & 426.157 \\
\hline$\alpha_{\mathrm{zZ}}$, a.u. & & -6.62195 & -3.22879 & 3.51065 & 7.59677 \\
\hline$\alpha_{Y Z}$, a.u. & & -6.21531 & -0.33418 & 7.56950 & -1.12186 \\
\hline$\alpha_{\mathrm{XZ}}$, a.u. & & 246.694 & 256.239 & 261.914 & 253.320 \\
\hline$\left\langle\alpha>\times 10^{-24} \mathrm{esu}^{\mathrm{b}}\right.$ & 22 & 63.33 & 65.70 & 66.64 & 64.74 \\
\hline$\Delta \alpha \times 10^{-24} \mathrm{esu}$ & & 47.85 & 49.91 & 50.27 & 49.55 \\
\hline$\beta x x x$, a.u. & & -311.565 & -254.708 & -278.249 & -205.497 \\
\hline$\beta x x y$, a.u. & & 163.254 & 170.091 & 168.919 & 179.192 \\
\hline$\beta$ xyy, a.u. & & -113.614 & -126.586 & -111.257 & -106.845 \\
\hline ßуyу, a.u. & & 8.21341 & 42.3811 & 95.0644 & 21.8794 \\
\hline$\beta x x z$, a.u. & & 70.4887 & 61.9425 & 2.81160 & 78.8312 \\
\hline$\beta x y z$, a.u. & & -7.3633 & -15.2491 & -54.4635 & -6.1162 \\
\hline ßyyz, a.u. & & -49.3368 & -45.3843 & -53.0683 & -53.0622 \\
\hline$\beta$ xzz, a.u. & & 29.0944 & 33.8242 & 71.6342 & 32.3890 \\
\hline$\beta y z z$, a.u. & & -28.8070 & -32.3737 & -22.8372 & -33.5310 \\
\hline$\beta z z z$, a.u. & & -41.7722 & -46.8760 & -61.9453 & -46.7887 \\
\hline$<\beta>\times 10^{-30} \mathrm{esu}^{\mathrm{c}}$ & 15.5 & 27.167 & 22.672 & 25.961 & 18.306 \\
\hline
\end{tabular}

a, b, c PNA results are taken from references [43-45]. 


\subsection{Molecular Electrostatic Potential (MEP)}

The electrophilic and nucleophilic attack as well as hydrogen bonding interactions in any molecular system can be explained in terms of the charge transfer and natural charges on active sites of the studied molecules [46]. DFT/B3LYP/6-311G (d,p) method of calculation of studied molecules (1-4) are calculated 3D MEP and ESP from optimized molecular structure are shown in "Figures 5 and $6 "$. Potential increases in the following order: red $<$ orange $<$ yellow $<$ green $<$ blue $[47,48]$. The results show that, in case of $1(\mathrm{X}=\mathrm{Y}=\mathrm{H})$ the negative region (red) is mainly over the $\mathrm{N}$ and $\mathrm{O}$ atomic sites, which is caused by the contribution of lone-pair electrons of nitrogen and oxygen atoms while the positive (blue) potential sites are around the hydrogen, sulfur and carbon atoms. A portion of the molecule that has negative electrostatic potential will be susceptible to electrophilic attack-the more negative the higher the tendency for electrophilic attack.

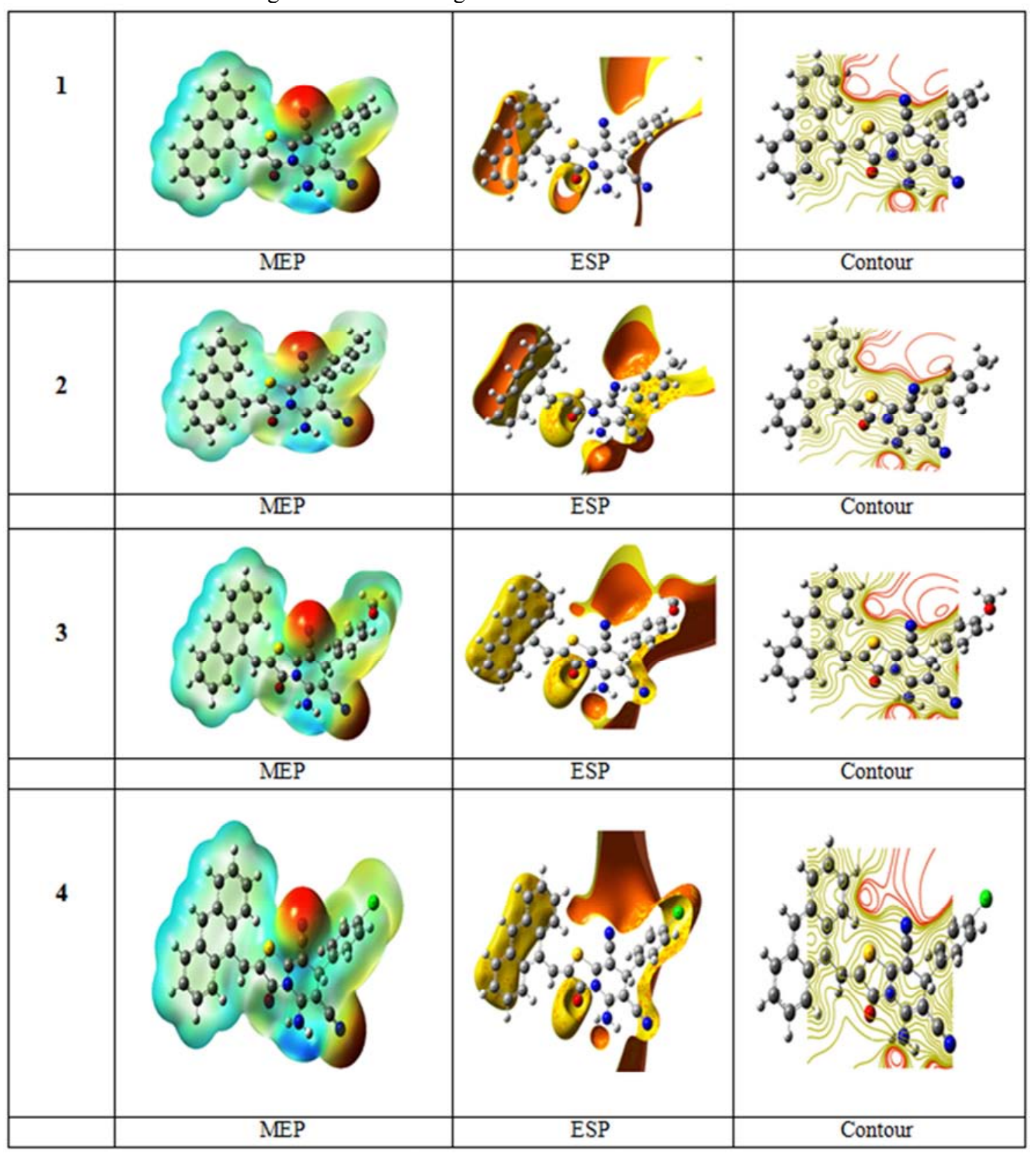

Figure 5. Molecular surfaces of studied compounds 1-4 at B3LYP/6-311G (d, p).

The color scheme for the MEP surface is as follows: red for electron rich, (partially negative charge); blue for electron deficient, (partially positive charge); light blue for (slightly electron deficient region); yellow for (slightly electron rich region); green for neutral (zero potential) respectively. 


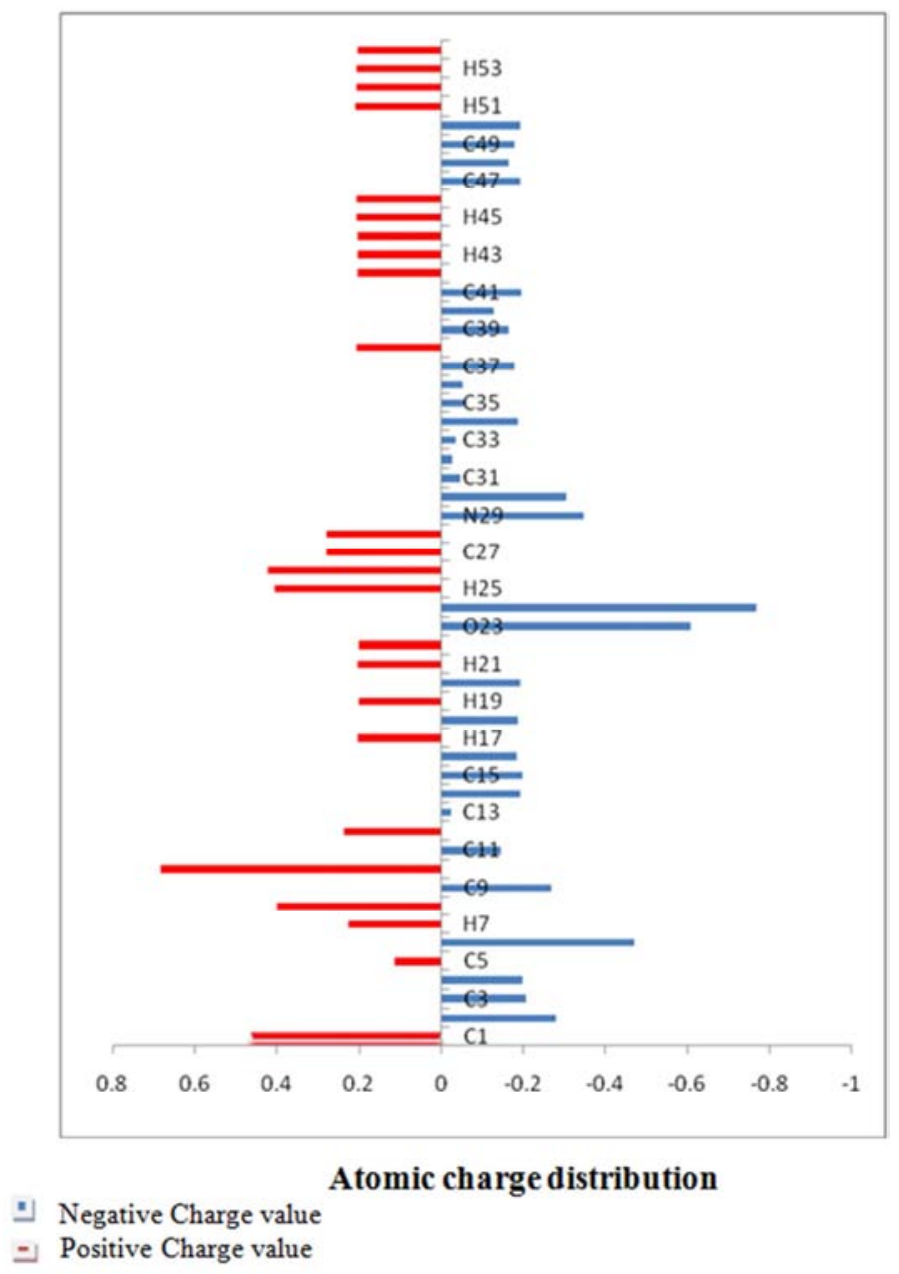

Figure 6. Atomic charge distribution (au) for 5-amino-2-(anthracen-9-ylmethylene)-3-oxo-7-phenyl-2,3-dihydro-7H-thiazolo[3,2-a]pyridine-6,8-dicarbonitrile 1 at $B 3 L Y P / 6-311 G(d, p)$ basis set.

\subsection{Electronic Absorption Spectra of Anthranyl Thiazolo[3,2-a]Pyridine Derivatives}

The electronic absorption spectra of novel thiazolo[3,2a]Pyridines having anthranyl moiety derivatives studied in this work 1-4 depend on the type and extent of interaction between different moieties. The possible types of interaction between subsystems are presented in Figure 7. For example, (i) Cross

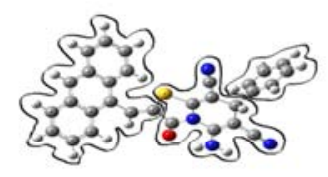

(i)

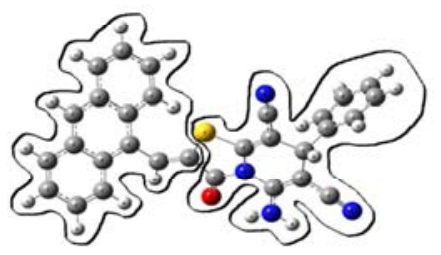

(iii) conjugation if no interaction between the fused thiazolo[3,2a]pyridine and the terminal phenyl group $\mathrm{Ph}-\mathrm{X}$ and the anthracene moiety, (ii) partial conjugation between $\mathrm{Ph}-\mathrm{X}$ and Anthranyl Thiazolo[3,2-a]Pyridine, (iii) partial conjugation between anthrathene moiety and Anthranyl Thiazolo[3,2a]Pyridine (iv) full conjugation between the three subsystems $\mathrm{Ph}-\mathrm{X}$, anthracene moiety, and thiazolo[3,2-a]pyridine.

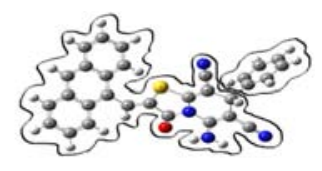

(i)

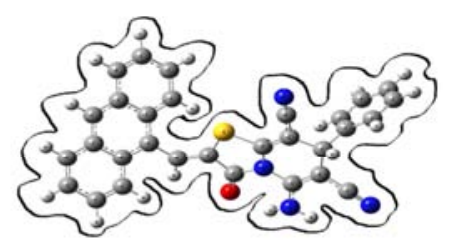

(iv)

Figure 7. The types of conjugation between different moieties of Anthranyl Thiazolo[3,2-a]Pyridine. 


\subsubsection{Electronic Absorption Spectra of Compound 1}

"Figure 8", and Table 7 presents the experimental and theoretical electronic absorption spectra of 1 in xylene and acetone. The spectrum of 1 is composed of three bands in the range $270-550 \mathrm{~nm}$. The spectrum in xylene shows two intense bands at $418 \mathrm{~nm}$, and $318 \mathrm{~nm}$. Increasing solvent polarity on going from xylene to actone results in a blue shift with the first band is shifted to $415 \mathrm{~nm}$, and the second band is shifted to $313 \mathrm{~nm}$, respectively. The two observed bands are assigned as $\left(\pi-\pi^{*}\right)$ transitions, as indicated by the values of molar absorptive $(\varepsilon=55000)$. Predicting and assigning the origin of the experimental spectrum of compound 1, one can calculate the theoretical gas phase transitions of the various subsystems a, b, and c as presented in "Figures 9-12", using CAM-B3LYP/6-311G $(\mathrm{d}, \mathrm{p})$. Five transitions are computed at 188.6, 234.6, 257.3, 312.4, and $371.8 \mathrm{~nm}$ for subsystem a; six transitions are computed at 129.4, 142.6, 168.5, 180.3, 218.0, and $235.9 \mathrm{~nm}$ for subsystem b; seven transitions are computed at 168.0, 187.7, 194.9, 232.2, 239.3, 260.6, and $283.6 \mathrm{~nm}$ for subsystem c; and five transitions are computed at 225.2, 251.5, 283.5, 310.7, and $403.8 \mathrm{~nm}$ for compound 1 . The correlation of the theoretical transitions between the various subsystems show that the transition at 232.2, 260.6 and $283.6 \mathrm{~nm}$ of subsystem c correlates with the transition at 225.2, 251.5 and $283.5 \mathrm{~nm}$ of compound 1. Moreover, three transition at 234.6, 257.3, and $312.4 \mathrm{~nm}$ of subsystem a correlates with that at $225.2,251.5$ and $310.7 \mathrm{~nm}$ of compound 1. While, two transition at 218.0 and $235.9 \mathrm{~nm}$ of subsystem b correlates with that at 225.2 and $251.5 \mathrm{~nm}$ of compound 1 . This indicates that the interaction of anthracene moiety and thiazolo[3,2-a]pyridine of subsystem c reproduces the partial conjugation (ii), which verifies the negligible influence of the interaction of $\mathrm{Ph}-\mathrm{X}$ (c. f. Figure 7). In order to account for the experimentally observed UV Spectra of 1 in xylene and acetone, it is essential to consider the theoretically calculated vertical transitions using TDDFT-CAM-B3LYP/6-311G (d, p) level. The experimental band at $418 \mathrm{~nm}$ (in xylene) is reproduced theoretically by using PCM (xylene), at 414 ( state I) nm, and in gas phase at $403.8 \mathrm{~nm}$ as shown in Table 7. The theoretical calculations of single point energy vertical excitations in acetone reproduce the wavelength of this band at $412 \mathrm{~nm}$ (state I), indicating that the calculated wavelength is lower than the observed wavelength. The second band observed experimentally at 318 $\mathrm{nm}$ in xylene, is reproduced theoretically at $311 \mathrm{~nm}$ (state II). The gas phase calculation gives a wavelength at $310.7 \mathrm{~nm}$. Moreover, In acetone, this same band appears at $313 \mathrm{~nm}$, where theoretical calculations in acetone reproduce this band at $308 \mathrm{~nm}$ (state II), as shown in Table 7 . The third $\left(\pi-\pi^{*}\right)^{1}$ state theoretically in xylene at $256 \mathrm{~nm}$ (state III), which involves the orbital's $\varphi_{123}$ and $\varphi_{127}$, in the transition. The gas phase calculation gives a wavelength at $251.5 \mathrm{~nm}$ (state III), which also involves orbital's $\varphi_{123}$ and $\varphi_{127}$. In acetone, this same band appears theoretically at $257 \mathrm{~nm}$, (state III), as shown in Table 7. The nature of the electronic transition can be inferred from examining the electron density contours of molecular orbitals. The four orbital's $\varphi_{123}, \varphi_{125}, \varphi_{126}$, and $\varphi_{127}$ respectively, involved in the theoretical transitions of 1 , are shown in "Figure 13", where the first, second and third bands involving $\varphi_{125}$ and $\varphi_{126} \& \varphi_{123}$ and $\varphi_{127}$ show a delocalization of electron density, and Charge Transfer CT character.

The NBO analysis of the studied compounds 1-4 provides an efficient method for studying intra-and intermolecular bonding and also provides a convenient basis for investigating charge transfer or conjugative interactions in molecular systems. Table 6 presents the second order perturbation energies of most interacting NBOs of 1-4 and the most important interaction between filled (donor) Lewis type NBOs and empty (acceptor) non-Lewis NBOs. The charge density maps of HOMO and LUMO for 1-4 are presented in "Figure 13". The results of NBO analysis of compound 1 tabulated in Table 6 indicate that there is a strong hyper conjugative interactions $\pi^{*} \mathrm{C}_{9}-\mathrm{C}_{11} \rightarrow \pi^{*} \mathrm{C}_{31}-\mathrm{C}_{33}$, LP (1) $\mathrm{N}_{24} \rightarrow \pi^{*} \mathrm{C}_{1}-\mathrm{C}_{2}$, LP (1) $\mathrm{N}_{6} \rightarrow \pi * \mathrm{C}_{4}-\mathrm{C}_{5}$, LP (2) $\mathrm{O}_{23} \rightarrow \sigma^{*} \mathrm{~N}_{6}-\mathrm{C}_{10}$, and $\pi \mathrm{C}_{1}-\mathrm{C}_{2} \rightarrow$ $\pi * \mathrm{C}_{27}-\mathrm{N}_{29}$, for 1 is $55.78,51.82,33.88,26.81$, and 23.58 $\mathrm{kcal} / \mathrm{mol}$, respectively. The $\mathrm{C}-\mathrm{N} \pi$ orbital in two cyano groups and amino group interacts equally well with pyridine ring. In fact, its interaction with the thiazolo ring is greater. Furthermore, the lone pair orbital of the nitrogen atom enjoys hyperconjugation with the $\mathrm{C} 10-\mathrm{O} 23$, and $\mathrm{C} 1-\mathrm{C} 2 \pi^{*}$ orbital. The oxygen and sulfur lone pair orbital's, on the other hand, interact essentially with the C5-N6 $\pi$ orbital of the thiazolo ring. It is surprising to notice a decrease in the population of the $\mathrm{NBO} \mathrm{C} 1-\mathrm{C} 2, \mathrm{C} 31-\mathrm{C} 33$, and $\mathrm{C} 10-\mathrm{O} 23$ reflecting a charge transfer away from the thiazolo[3,2-a]pyridine ring. In conclusion, 1 enjoys the linear conjugation that is responsible for the observed spectrum. No specific part of the molecule manifests itself in the observed spectrum.

Table 6. Second Order Perturbation Interaction Energy Values Computed in the NBO Basis for the studied compounds 1-4, calculated at B3LYP/6-311G (d, p).

\begin{tabular}{|c|c|c|c|c|c|}
\hline Compound & Donor & Acceptor & $\mathrm{E}^{(2) \mathrm{a}}(\mathrm{kcal} / \mathrm{mol})$ & NBO & Population \\
\hline \multirow{11}{*}{$1 \mathrm{H}$} & $\pi \mathrm{C} 1-\mathrm{C} 2$ & $\pi * \mathrm{C} 27-\mathrm{N} 29$ & 23.58 & $\mathrm{C} 1-\mathrm{C} 2$ & 1.84983 \\
\hline & $\pi \mathrm{C} 9-\mathrm{C} 11$ & $\pi^{*} \mathrm{C} 10-\mathrm{O} 23$ & 20.87 & C9-C11 & 1.86448 \\
\hline & $\sigma \mathrm{C} 11-\mathrm{H} 12$ & $\sigma^{*} \mathrm{~S} 8-\mathrm{C} 9$ & 10.96 & C11-H12 & 1.95503 \\
\hline & $\pi \mathrm{C} 32-\mathrm{C} 34$ & $\pi^{*} \mathrm{C} 37-\mathrm{C} 41$ & 25.59 & C32-C34 & 1.51731 \\
\hline & $\pi \mathrm{C} 35-\mathrm{C} 39$ & $\pi^{*} \mathrm{C} 36-\mathrm{C} 40$ & 23.32 & C35-C39 & 1.50209 \\
\hline & LP (1) N6 & $\pi * \mathrm{C} 4-\mathrm{C} 5$ & 33.88 & LP (1) N6 & 1.61488 \\
\hline & LP (1) N6 & $\pi^{*} \mathrm{C} 10-\mathrm{O} 23$ & 50.05 & LP (2) S8 & 1.73751 \\
\hline & LP (2) S8 & $\pi^{*} \mathrm{C} 4-\mathrm{C} 5$ & 23.87 & LP (1)O23 & 1.97186 \\
\hline & $\mathrm{LP}(1) \mathrm{O} 23$ & $\mathrm{RY}{ }^{*} \mathrm{C} 10$ & 14.14 & $\mathrm{LP}(2) \mathrm{O} 23$ & 1.84468 \\
\hline & $\mathrm{LP}(2) \mathrm{O} 23$ & $\sigma * \mathrm{~N} 6-\mathrm{C} 10$ & 26.81 & LP(1) N24 & 1.74481 \\
\hline & $\mathrm{LP}(2) \mathrm{O} 23$ & $\sigma^{*} \mathrm{C} 9-\mathrm{C} 10$ & 18.74 & LP(1) N29 & 1.96851 \\
\hline
\end{tabular}



Spectra of Some Novel Thiazolo[3,2-a]Pyridine Derivatives Bearing Anthracenyl Moiety

\begin{tabular}{|c|c|c|c|c|c|}
\hline Compound & Donor & Acceptor & $\mathbf{E}^{(2) \mathrm{a}}(\mathrm{kcal} / \mathrm{mol})$ & NBO & Population \\
\hline \multirow{13}{*}{$2 \mathrm{CH} 3$} & LP(1) N24 & $\pi^{*} \mathrm{C} 1-\mathrm{C} 2$ & 51.82 & $\mathrm{C} 1-\mathrm{C} 2$ & 0.35144 \\
\hline & LP(1) N29 & $\mathrm{RY}{ }^{*} \mathrm{C} 27$ & 16.62 & C31-C33 & 0.42571 \\
\hline & $\pi * \mathrm{C} 1-\mathrm{C} 2$ & $\pi^{*} \mathrm{C} 27-\mathrm{N} 29$ & 19.00 & $\mathrm{C} 10-\mathrm{O} 23$ & 0.31646 \\
\hline & $\pi^{*}$ C9-C11 & $\pi^{*} \mathrm{C} 31-\mathrm{C} 33$ & 55.78 & & \\
\hline & $\pi^{*} \mathrm{C} 10-\mathrm{O} 23$ & $\pi^{*} \mathrm{C} 9-\mathrm{C} 11$ & 47.61 & & \\
\hline & $\pi \mathrm{C} 47-\mathrm{C} 49$ & $\pi^{*} \mathrm{C} 46-\mathrm{C} 48$ & 17.10 & C47-C49 & 1.76398 \\
\hline & LP (1) N6 & $\pi^{*} \mathrm{C} 10-\mathrm{O} 23$ & 50.19 & LP (2) S8 & 1.73776 \\
\hline & LP (2) S8 & $\pi^{*} \mathrm{C} 4-\mathrm{C} 5$ & 23.83 & LP (1)N6 & 1.61466 \\
\hline & LP (2)O23 & $\sigma^{*} \mathrm{~N} 6-\mathrm{C} 10$ & 26.74 & LP(1) N24 & 1.74631 \\
\hline & LP(1) N24 & $\pi * \mathrm{C} 1-\mathrm{C} 2$ & 51.24 & $\mathrm{LP}(2) \mathrm{O} 23$ & 1.84501 \\
\hline & $\pi^{*} \mathrm{C} 1-\mathrm{C} 2$ & $\pi^{*} \mathrm{C} 27-\mathrm{N} 29$ & 18.97 & $\mathrm{C} 1-\mathrm{C} 2$ & 0.35064 \\
\hline & $\pi^{*} \mathrm{C} 9-\mathrm{C} 11$ & $\pi^{*} \mathrm{C} 31-\mathrm{C} 33$ & 56.61 & C31-C33 & 0.42485 \\
\hline & $\pi^{*} \mathrm{C} 10-\mathrm{O} 23$ & $\pi^{*} \mathrm{C} 9-\mathrm{C} 11$ & 47.32 & $\mathrm{C} 10-\mathrm{O} 23$ & 0.31674 \\
\hline \multirow[t]{9}{*}{$3 \mathrm{OCH} 3$} & $\sigma \mathrm{C} 11-\mathrm{H} 12$ & $\sigma^{*} \mathrm{~S} 8-\mathrm{C} 9$ & 11.02 & C11-H12 & 1.95484 \\
\hline & LP (1) N6 & $\pi^{*} \mathrm{C} 4-\mathrm{C} 5$ & 33.65 & LP (1) N6 & 1.61455 \\
\hline & LP (1) N6 & $\pi^{*} \mathrm{C} 10-\mathrm{O} 23$ & 50.36 & LP (2) S8 & 1.73841 \\
\hline & LP (2) S8 & $\pi^{*} \mathrm{C} 4-\mathrm{C} 5$ & 23.66 & LP (1)N24 & 1.74787 \\
\hline & LP(1) N24 & $\pi^{*} \mathrm{C} 1-\mathrm{C} 2$ & 50.97 & LP (2)O54 & 1.83780 \\
\hline & LP (2)O54 & $\sigma^{*} \mathrm{C} 18-\mathrm{C} 20$ & 31.04 & $\mathrm{C} 1-\mathrm{C} 2$ & 0.34997 \\
\hline & $\pi * \mathrm{C} 1-\mathrm{C} 2$ & $\pi^{*} \mathrm{C} 27-\mathrm{N} 29$ & 19.03 & C31-C33 & 0.42542 \\
\hline & $\pi^{*} \mathrm{C} 9-\mathrm{C} 11$ & $\pi^{*} \mathrm{C} 31-\mathrm{C} 33$ & 58.44 & $\mathrm{C} 10-\mathrm{O} 23$ & 0.31769 \\
\hline & $\pi^{*} \mathrm{C} 10-\mathrm{O} 23$ & $\pi^{*} \mathrm{C} 9-\mathrm{C} 11$ & 47.88 & & \\
\hline \multirow[t]{12}{*}{$4 \mathrm{Cl}$} & $\pi \mathrm{C} 9-\mathrm{C} 11$ & $\pi^{*} \mathrm{C} 10-\mathrm{O} 22$ & 21.20 & C9-C11 & 1.86172 \\
\hline & $\pi \mathrm{C} 46-\mathrm{C} 48$ & $\pi^{*} \mathrm{C} 45-\mathrm{C} 47$ & 17.17 & $\mathrm{C} 46-\mathrm{C} 48$ & 1.76289 \\
\hline & LP (1) N6 & $\pi^{*} \mathrm{C} 4-\mathrm{C} 5$ & 34.25 & LP (1) N6 & 1.61550 \\
\hline & LP (1) N6 & $\pi^{*} \mathrm{C} 10-\mathrm{O} 22$ & 49.64 & LP (2) S8 & 1.73641 \\
\hline & LP (2) S8 & $\pi * \mathrm{C} 4-\mathrm{C} 5$ & 24.15 & LP (1)N23 & 1.74175 \\
\hline & LP(1) N23 & $\pi^{*} \mathrm{C} 1-\mathrm{C} 2$ & 52.68 & LP (3) Cl54 & 1.92713 \\
\hline & LP (3)Cl54 & $\pi^{*} \mathrm{C} 16-\mathrm{C} 19$ & 12.42 & $\mathrm{C} 1-\mathrm{C} 2$ & 0.35469 \\
\hline & $\pi^{*} \mathrm{C} 1-\mathrm{C} 2$ & $\pi^{*} \mathrm{C} 26-\mathrm{N} 28$ & 18.84 & C30-C32 & 0.42716 \\
\hline & $\pi^{*} \mathrm{C} 9-\mathrm{C} 11$ & $\pi^{*} \mathrm{C} 30-\mathrm{C} 32$ & 56.71 & $\mathrm{C} 10-\mathrm{O} 22$ & 0.31575 \\
\hline & $\pi^{*} \mathrm{C} 10-\mathrm{O} 22$ & $\pi^{*} \mathrm{C} 9-\mathrm{C} 11$ & 47.19 & C16-C19 & 0.37962 \\
\hline & $\pi^{*} \mathrm{C} 16-\mathrm{C} 19$ & $\pi^{*} \mathrm{C} 13-\mathrm{C} 14$ & 206.92 & C13-C14 & 0.34433 \\
\hline & $\pi * \mathrm{C} 16-\mathrm{C} 19$ & $\pi * \mathrm{C} 15-\mathrm{C} 18$ & 249.52 & C15-C18 & 0.31072 \\
\hline
\end{tabular}

${ }^{a} E^{(2)}$ means energy of hyperconjugative interactions (stabilization energy).

$\mathrm{LP}_{(\mathrm{n})}$ is a valence lone pair orbital $(\mathrm{n})$ on atom.

Table 7. Theoretical and experimental UV spectra of 1 , calculated at CAM-B3LYP/6-311G (d, $p)$.

\begin{tabular}{|c|c|c|c|c|c|c|c|c|}
\hline \multirow{3}{*}{ state } & \multicolumn{8}{|l|}{ TD-Theoretical } \\
\hline & \multicolumn{4}{|l|}{ Gas phase } & \multicolumn{4}{|l|}{ Xylene } \\
\hline & Config uration & Coefficient & f & $\lambda, \mathrm{nm}$ & Configuration & Coefficient & f & $\lambda, \mathrm{nm}$ \\
\hline \multirow[t]{3}{*}{ I } & $125-126$ & 0.694 & 0.412 & 403.8 & $125-126$ & 0.692 & 0.494 & 414 \\
\hline & $120-126$ & -0.15 & 0.115 & 310.7 & $123-126$ & -0.398 & 0.291 & 311 \\
\hline & $123-126$ & 0.626 & & & $124-126$ & 0.468 & & \\
\hline \multirow[t]{6}{*}{ II } & $123-127$ & -0.16 & & & $124-127$ & $0.215-$ & & \\
\hline & $124-126$ & 0.108 & & & $125-127$ & $0.185-$ & & \\
\hline & $124-127$ & -0.10 & & & & & & \\
\hline & $118-127$ & 0.117 & 0.399 & 251.5 & $122-126$ & -0.267 & 0.952 & 256 \\
\hline & $119-126$ & -0.25 & & & $123-127$ & 0.363 & & \\
\hline & $122-126$ & -0.14 & & & $123-128$ & -0.27 & & \\
\hline \multirow{4}{*}{ III } & $123-127$ & 0.472 & & & $124-128$ & $0.227-$ & & \\
\hline & $123-128$ & $0.17-$ & & & $125-128$ & $0.205-$ & & \\
\hline & $124-128$ & -0.22 & & & $125-129$ & 0.267 & & \\
\hline & $125-128$ & $0.12-$ & & & & & & \\
\hline
\end{tabular}

Table 7. Continued.

\begin{tabular}{|c|c|c|c|c|c|c|}
\hline \multirow{3}{*}{ state } & \multicolumn{4}{|l|}{ TD-Theoretical } & \multicolumn{2}{|c|}{ Experimental } \\
\hline & \multicolumn{4}{|l|}{ Acetone } & \multirow{2}{*}{$\begin{array}{l}\text { Acetone } \\
\lambda, g_{\mathrm{nm}}\end{array}$} & \multirow{2}{*}{$\begin{array}{l}\text { Xylene } \\
\lambda, \mathrm{nm}\end{array}$} \\
\hline & Configuration & Coefficient & f & $\lambda, \mathbf{n m}$ & & \\
\hline $\mathrm{I}$ & $125-126$ & 0.692 & 0.471 & 412 & 415 & 418 \\
\hline \multirow{4}{*}{ II } & $123-126$ & 0.448 & \multirow{4}{*}{0.303} & \multirow{4}{*}{308} & \multirow{4}{*}{313} & \multirow{4}{*}{318} \\
\hline & $124-126$ & -0.43 & & & & \\
\hline & $124-127$ & 0.209 & & & & \\
\hline & $125-127$ & 0.137 & & & & \\
\hline
\end{tabular}




\begin{tabular}{|c|c|c|c|c|c|c|}
\hline \multirow{3}{*}{ state } & \multicolumn{4}{|l|}{ TD-Theoretical } & \multicolumn{2}{|c|}{ Experimental } \\
\hline & \multicolumn{4}{|l|}{ Acetone } & \multirow{2}{*}{$\begin{array}{l}\text { Acetone } \\
\lambda,{ }_{\text {nm }}\end{array}$} & \multirow{2}{*}{$\begin{array}{l}\text { Xylene } \\
\lambda, \mathrm{nm}\end{array}$} \\
\hline & Configuration & Coefficient & f & $\lambda, \mathbf{n m}$ & & \\
\hline \multirow{8}{*}{ III } & $119-126$ & 0.331 & \multirow{8}{*}{0.542} & \multirow{8}{*}{257} & & \\
\hline & $119-127$ & 0.117 & & & & \\
\hline & $122-126$ & 0.225 & & & & \\
\hline & $123-127$ & $0.244-$ & & & & \\
\hline & $123-128$ & 0.255 & & & & \\
\hline & $124-128$ & 0.205 & & & & \\
\hline & $125-128$ & 0.268 & & & & \\
\hline & $125-129$ & $0.185-$ & & & & \\
\hline
\end{tabular}

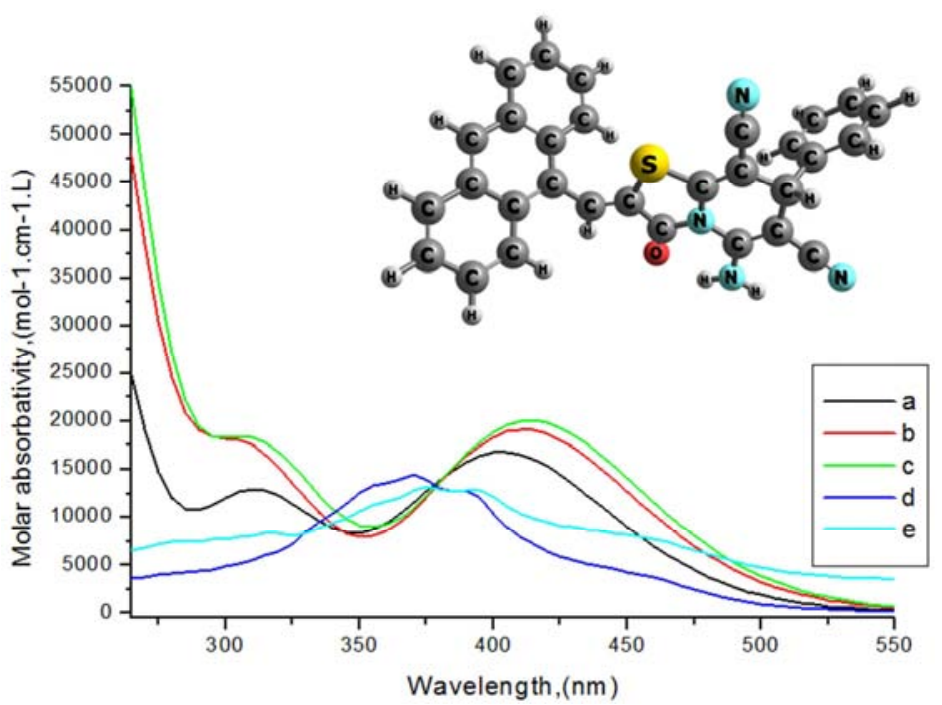

Figure 8. Electronic absorption spectra of 1, (a) theoretical in gas phase, (b) theoretical in acetone, (c) theoretical in xylene, (d) experimental in acetone, (e) experimental in xylene.

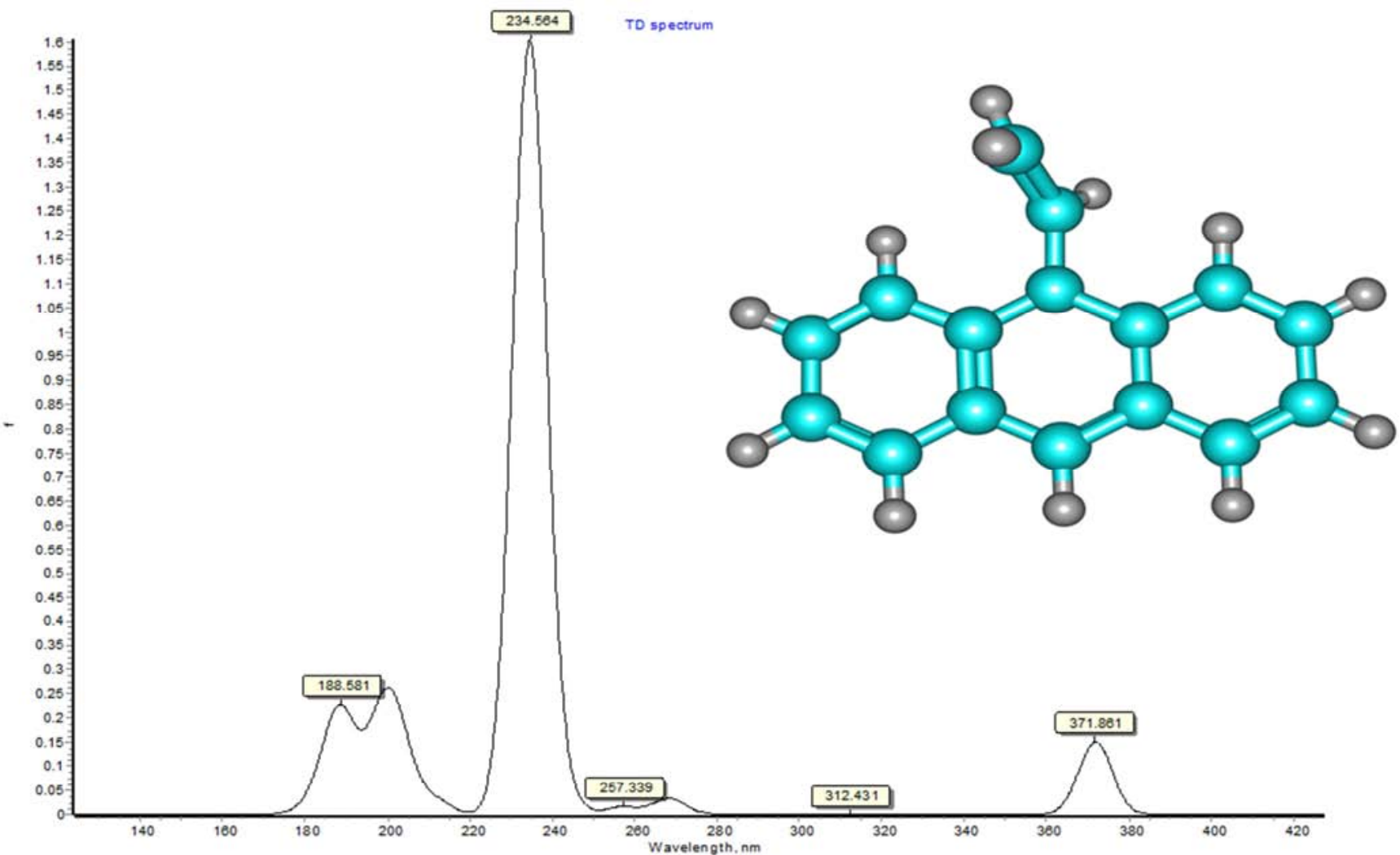

Figure 9. Theoretical transitions at TD-DFT B3LYP/6-311G (d, p) level of theory of (a) 9-vinylanthracene. 


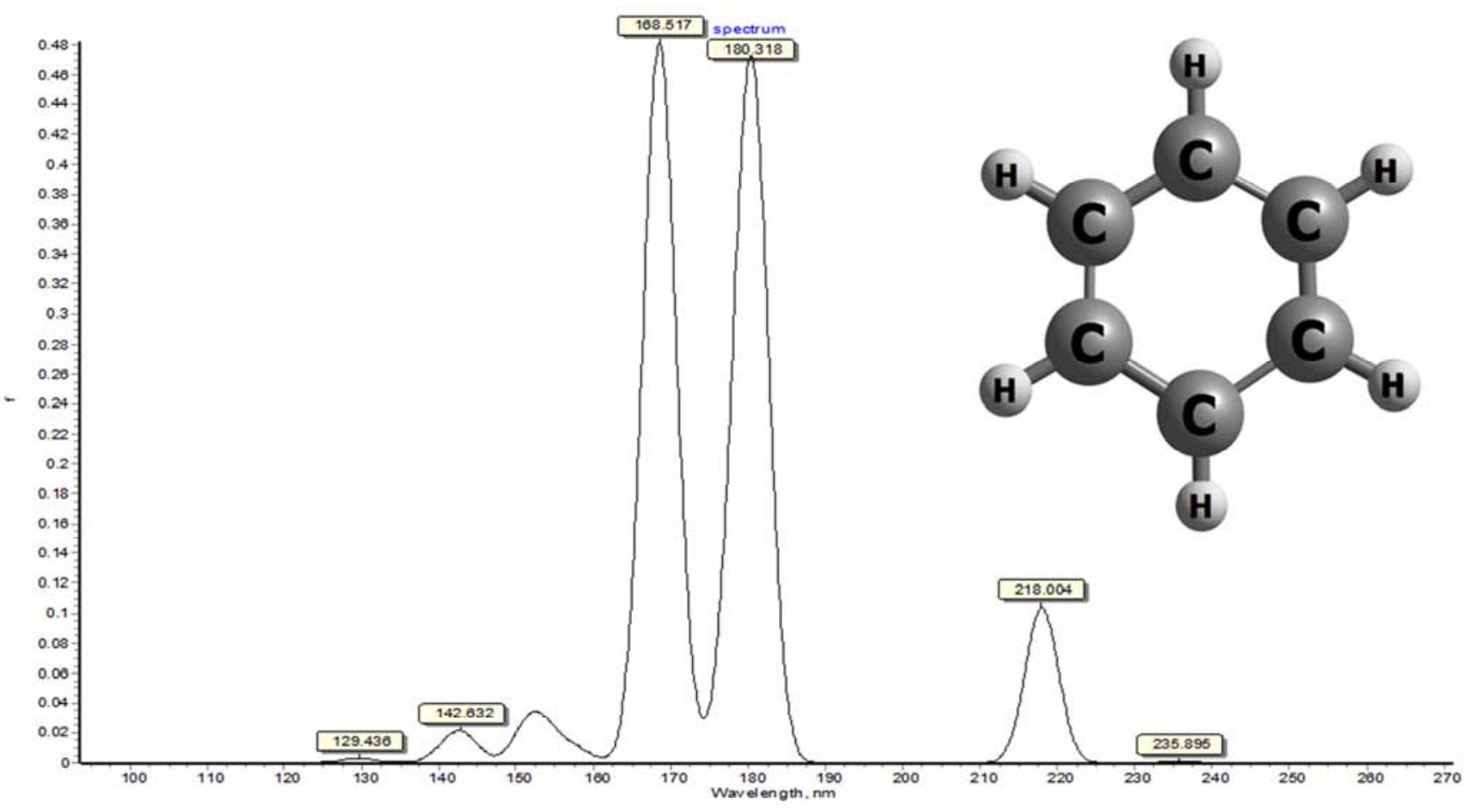

Figure 10. Theoretical transitions at TD-DFT B3LYP/6-311G $(d, p)$ level of theory of (b) benzene.

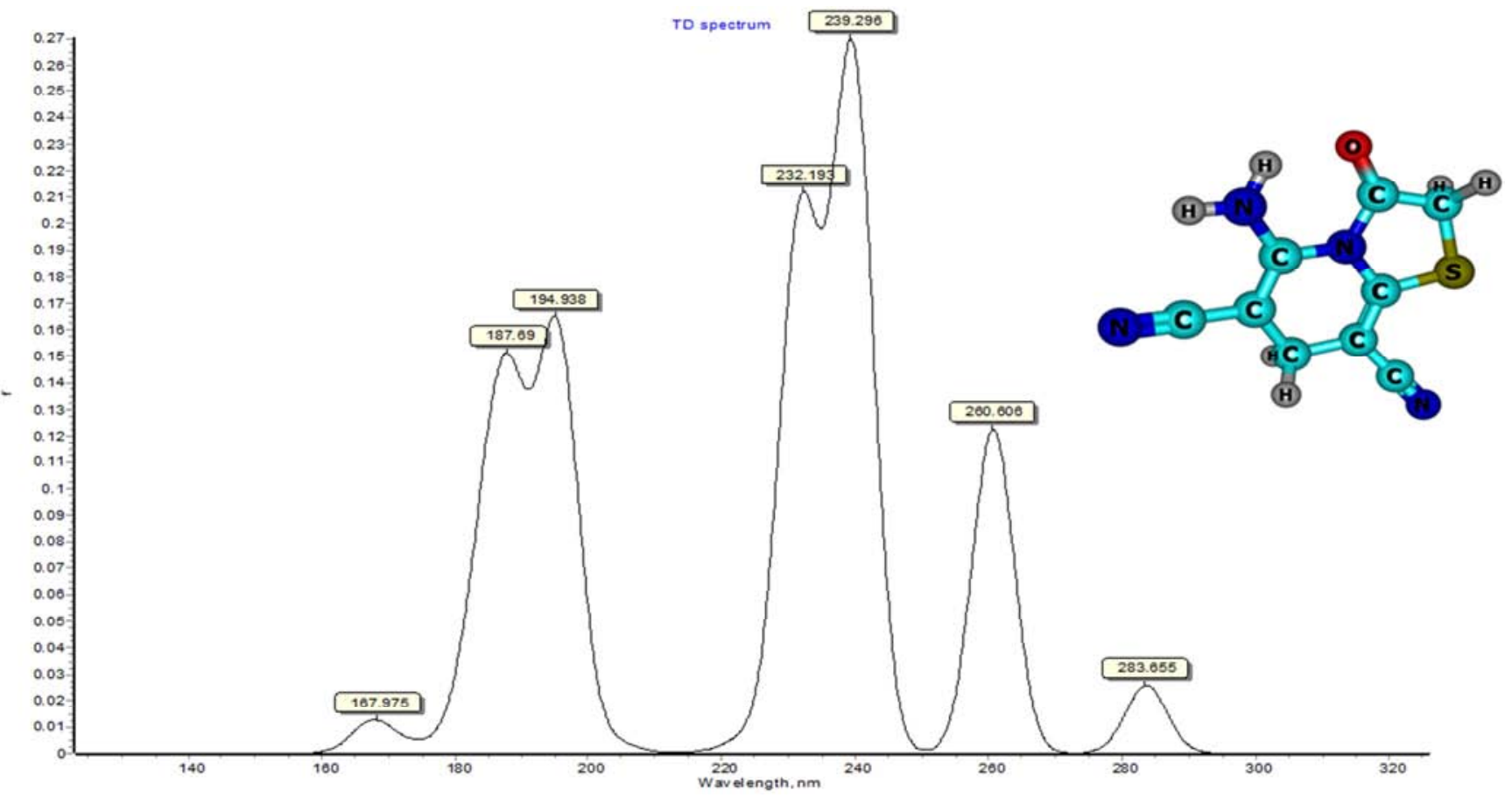

Figure 11. Theoretical transitions at TD-DFT B3LYP/6-311G (d, p) level of theory of (c) 5-amino-3-oxo-3,7-dihydro-2H-thiazolo[3,2-a]pyridine-6,8dicarbonitrile. 


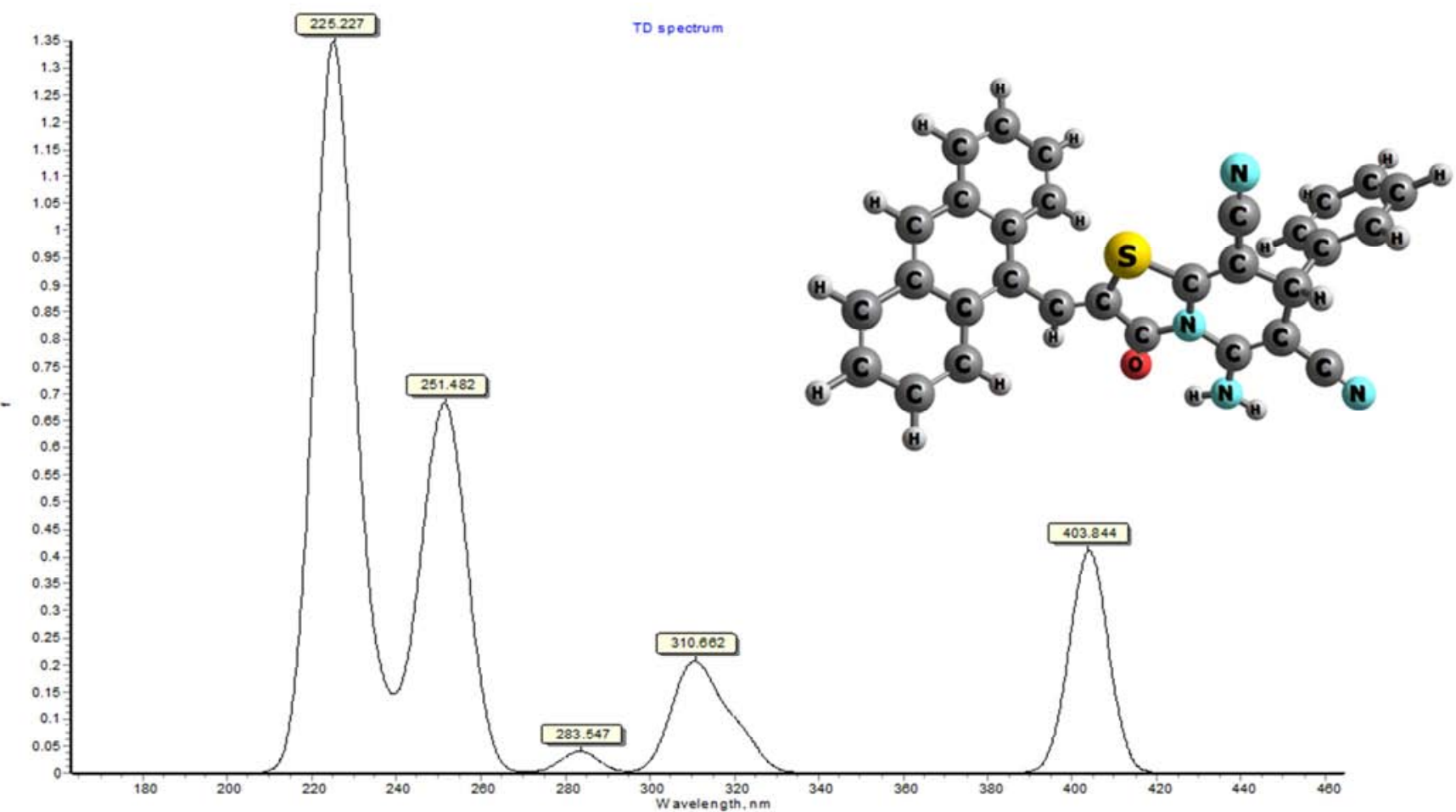

Figure 12. Theoretical transitions at TD-DFT B3LYP/6-311G (d, p) level of theory of compound 1 5-amino-2-(anthracen-9-ylmethylene)-3-oxo-7-phenyl-2,3dihydro-7H thiazolo[3,2-a]pyridine-6,8-dicarbonitrile.

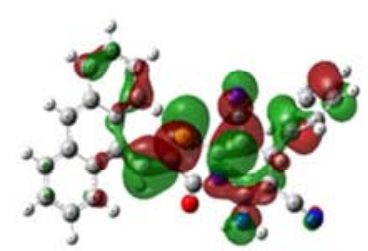

$\Phi_{123}$

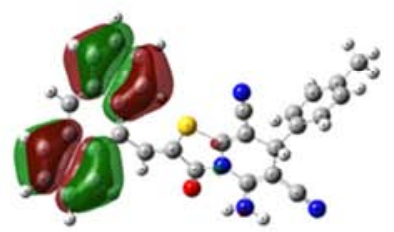

$\Phi_{123}$

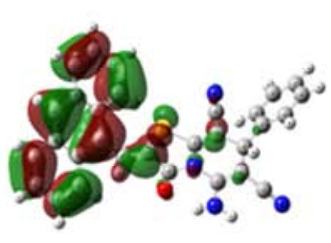

$\Phi_{125}$

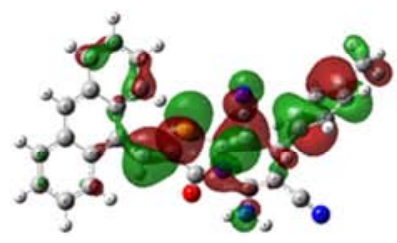

$\Phi_{127}$

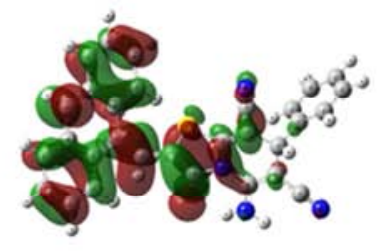

$\Phi_{126}$

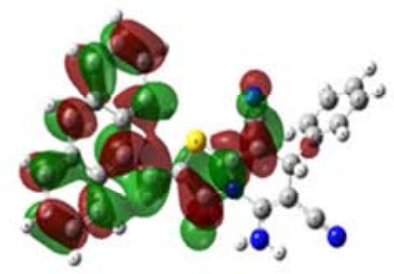

$\Phi_{127}$

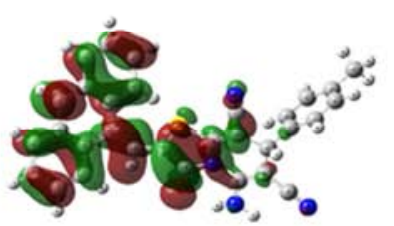

$\Phi_{130}$

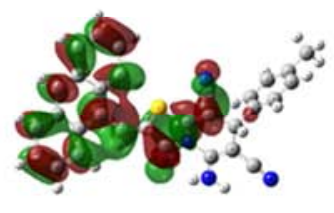

$\Phi_{131}$

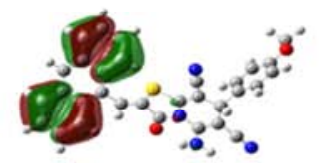

$\Phi_{127}$
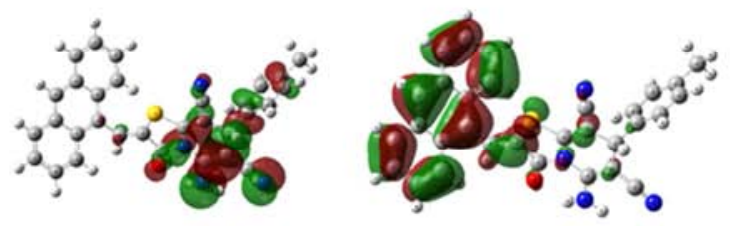

$\Phi_{128}$

$\Phi_{129}$

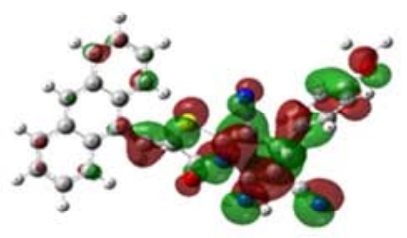

$\Phi_{131}$ 


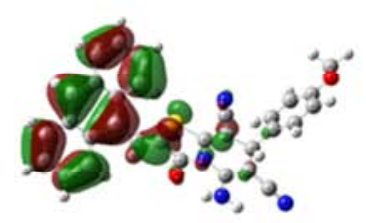

$\Phi_{133}$

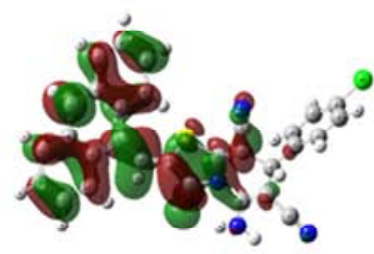

$\Phi_{134}$

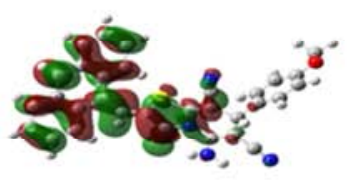

$\Phi_{134}$

$\Phi_{131}$

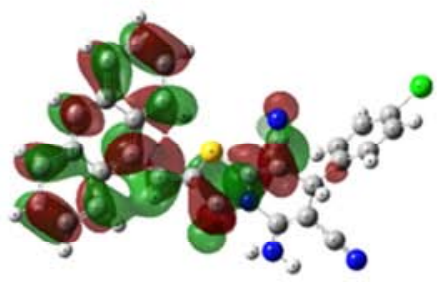

$\Phi_{135}$
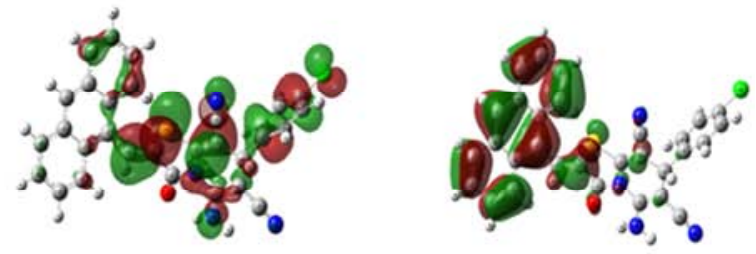

$\Phi_{133}$

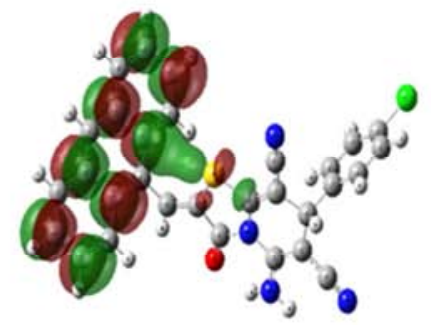

$\Phi_{137}$

Figure 13. Electron density contours of the studied compounds 1-4.

\subsubsection{Electronic Absorption Spectra of Compound 2}

Compound 2 results when our insertion of $\mathrm{CH} 3$ group in position $\mathrm{X}$ of $\mathrm{Ph}-\mathrm{X}$ in compound 1. "Figure 14", and Table 8 elucidate the experimental and theoretical electronic absorption spectra of compound 2 in two solvents xelene and acetone. In non-polar solvent (xylene), the experimental spectrum is composed of two bands, at 417 $\mathrm{nm}$, and $315 \mathrm{~nm}$. The blue shift of the two bands, results from increasing solvent polarity from xylene to acetone where the first band is shifted to $414 \mathrm{~nm}$, and the second band is shifted to $313 \mathrm{~nm}$, respectively. Furthermore, The two observed bands are assigned as $\left(\pi-\pi^{*}\right)$ transitions, based on the values of molar absorptive $(\varepsilon=50000)$, due to, increasing solvent polarity causes a marked increase in the intensity of both bands. CAM / B3LYP/6-311G (d, p) level used for the interpretation of the experimentally observed UV Spectra of 2 in non-polar solvent (xylene) and polarsolvent (acetone) these requires the theoretical calculations of the vertical transitions. State (I) the non-polar solvent (xylene), shows the spectrum band experimentally at 417 $\mathrm{nm}$ is reproduced theoretically at $414 \mathrm{~nm}$ (state I), as shown in Table 8, which involves orbital's $\varphi_{129}$ and $\varphi_{130}$, showing a good agreement between the observed wavelength with the calculated wavelength. The gas phase computed theoretically give a vertical excitation at $403 \mathrm{~nm}$ (state I). Increasing solvent polarity results in a blue shift of $\lambda_{\max }$ of this band to $414 \mathrm{~nm}$. The polar solvent (acetone) appeared theoretically band at $410 \mathrm{~nm}$ (state I). The second band observed experimentally in xylene at $315 \mathrm{~nm}$, is reproduced theoretically at $311 \mathrm{~nm}$ (state II), indicating that the orbital's $\varphi_{128}$ and $\varphi_{130}$ are involved in this transition. Theoretical gas phase calculations give a wavelength at $309 \mathrm{~nm}$ (state II). This same band is observed at $313 \mathrm{~nm}$ in acetone, where theoretical calculations in acetone reproduces this band at $307 \mathrm{~nm}$ (state II), which is lower than the observed wavelength, where the orbital's $\varphi_{127}$ and $\varphi_{130}$ are involved in this transition. The third band theoretically in xylene at 257 $\mathrm{nm}$, (state III), indicating that the orbital's $\varphi_{127}$ and $\varphi_{131}$ are involved in this transition. Theoretical gas phase calculations give a wavelength at $253 \mathrm{~nm}$ (state III), this same band theoretical calculations in acetone at $256 \mathrm{~nm}$ (state III), where the orbital's $\varphi_{123}$ and $\varphi_{130}$ are involved in this transition. The six orbital's $\varphi_{123}, \varphi_{127}, \varphi_{128}, \varphi_{129}, \varphi_{130}$ and $\varphi_{131}$ involved in the theoretical transitions of 2 , are shown in "Figure 13". The first band which involves $\varphi_{129}$ and $\varphi_{130}$ has electron density delocalization, while orbital's $\varphi_{123}, \varphi_{127}$, $\varphi_{128}$ and $\varphi_{131}$ have a Charge Transfer CT character. The results of NBO analysis of compound 2 tabulated in Table 6 indicate that there is a strong hyper conjugative interactions $\pi * \mathrm{C}_{9}-\mathrm{C}_{11} \rightarrow \pi * \mathrm{C}_{31}-\mathrm{C}_{33}$, LP (1) $\mathrm{N}_{24} \rightarrow \pi^{*} \mathrm{C}_{1}-\mathrm{C}_{2}$, LP (1) $\mathrm{N}_{6} \rightarrow$ $\pi^{*} \mathrm{C}_{10}-\mathrm{O}_{23}, \pi^{*} \mathrm{C}_{10}-\mathrm{O}_{23} \rightarrow \pi * \mathrm{C}_{9}-\mathrm{C}_{11}, \mathrm{LP}$ (2) $\mathrm{O}_{23} \rightarrow \sigma^{*} \mathrm{~N}_{6}-\mathrm{C}_{10}$, LP (2) $\mathrm{S}_{8} \rightarrow \pi^{*} \mathrm{C}_{4}-\mathrm{C}_{5}$, and $\pi^{*} \mathrm{C}_{1}-\mathrm{C}_{2} \rightarrow \pi^{*} \mathrm{C}_{27}-\mathrm{N}_{29}$, for 2 is $56.16,51.24,50.19,47.32,26.74,23.83$ and $18.97 \mathrm{kcal} / \mathrm{mol}$, respectively. NBO analysis of the $\mathrm{p}-\mathrm{CH} 3$ derivative Table 6 indicates that it retained the extended conjugation of 1 as revealed by the interaction of $\mathrm{C}-\mathrm{N}$ NBOs with those of pyridine ring. Furthermore, the interaction of the nitrogen lone orbital's with the $\mathrm{C} 10-\mathrm{O} 23$, and $\mathrm{C} 1-\mathrm{C} 2 \pi^{*}$ orbital is marked. The population of the NBO C1-C2, C31-C33, and $\mathrm{C} 10-\mathrm{O} 23$ reflecting a charge transfer away from the thiazolo[3,2-a]pyridine ring. This is also evident in the case of the population of the nitrogen lone orbital LP (1) N6. 
Table 8. Theoretical and experimental UV spectra of 2, calculated at CAM-B3LYP/6-311G (d, p).

\begin{tabular}{|c|c|c|c|c|c|c|c|c|}
\hline \multirow{3}{*}{ state } & \multicolumn{8}{|l|}{ TD-Theoretical } \\
\hline & \multicolumn{4}{|l|}{ Gas phase } & \multicolumn{4}{|l|}{ Xylene } \\
\hline & Config uration & Coefficient & f & $\lambda, \mathbf{n m}$ & Config uration & Coefficient & f & $\lambda, \mathbf{n m}$ \\
\hline I & $129-130$ & 0.694 & 0.418 & 403 & $129-130$ & 0.692 & 0.500 & 414 \\
\hline \multirow{5}{*}{ II } & $124-130$ & -0.10 & 0.136 & 309 & $126-130$ & -0.113 & 0.288 & 311 \\
\hline & $126-130$ & 0.265 & & & $127-130$ & -0.416 & & \\
\hline & $127-130$ & 0.585 & & & $128-130$ & 0.433 & & \\
\hline & $127-131$ & $0.15-$ & & & $128-131$ & 0.204 & & \\
\hline & & & & & $129-131$ & 0.199 & & \\
\hline \multirow{7}{*}{ III } & $122-131$ & $0.11-$ & 0.376 & 253 & $123-130$ & 0.183 & 0.976 & 257 \\
\hline & $123-130$ & -0.34 & & & $125-130$ & 0.282 & & \\
\hline & $125-130$ & -0.14 & & & $126-131$ & 0.105 & & \\
\hline & $126-131$ & 0.131 & & & $127-131$ & 0.314 & & \\
\hline & $127-131$ & 0.410 & & & $127-132$ & $0.257-$ & & \\
\hline & $127-132$ & -0.17 & & & $128-132$ & -0.230 & & \\
\hline & $128-132$ & $0.22-$ & & & $129-132$ & -0.190 & & \\
\hline
\end{tabular}

Table 8. Continued.

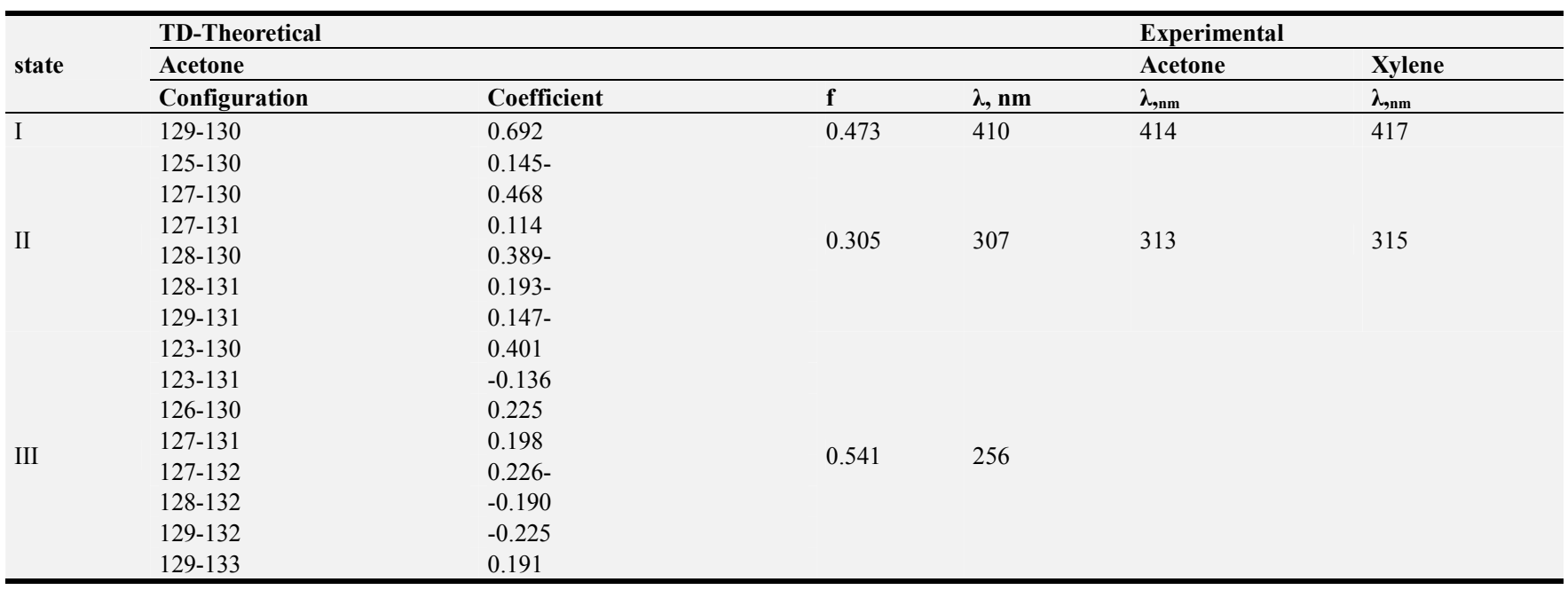

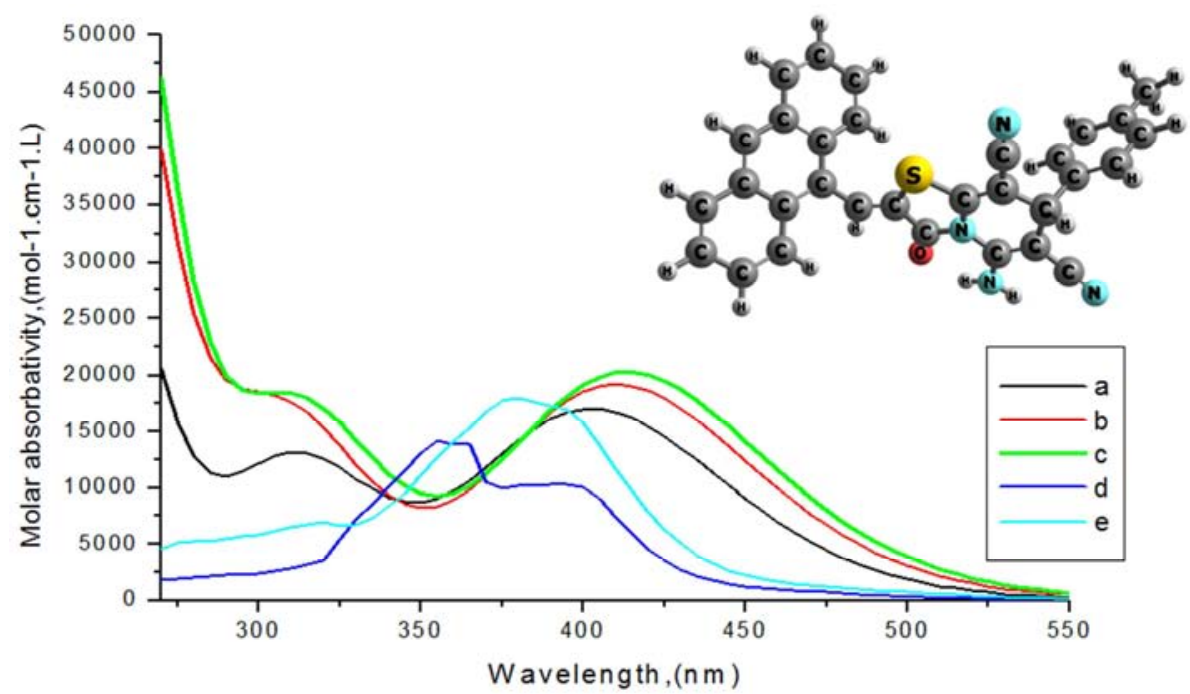

Figure 14. Electronic absorption spectra of 2, (a) theoretical in gas phase, (b) theoretical in acetone, (c) theoretical in xylene, (d) experimental in acetone, (e) experimental in xylene.

\subsubsection{Electronic Absorption Spectra of Compound 3}

To complete our investigation of substituent effect on the electronic structure and spectra of compound 1, we introduce $\mathrm{OCH} 3$-group in position $\mathrm{X}$ in $\mathrm{Ph}-\mathrm{X}$ of compound 1 gives compound 3. The experimental and theoretical electronic 
absorption spectra of compound 3 in xylene and acetone are shown in "Figure 15", and Table 9. The experimental spectrum in xylene is composed of two bands at $419 \mathrm{~nm}$, and $316 \mathrm{~nm}$. The change of solvent polarity from xylene to acetone results in a blue shift of the two bands, where the first band is shifted to $416 \mathrm{~nm}$, and the second band is shifted to $313 \mathrm{~nm}$, respectively. Furthermore, increasing solvent polarity causes a marked increase in the intensity of both bands. The values of molar absorptive $(\varepsilon=45000)$ indicates that the two observed bands have $\pi-\pi^{*}$ character. The theoretical vertical transitions using CAM / B3LYP / 6-311G $(\mathrm{d}, \mathrm{p})$ level is valuable for the analysis of the experimental UV Spectra of 3 in xylene and acetone, which gives values for $\lambda_{\max }$ of $415 \mathrm{~nm}$ (state I) for the first band, $311 \mathrm{~nm}$ (state II) for the second band, $258 \mathrm{~nm}$ (state III) for the third band, as shown in Table 9. Theoretical transitions in the gas phase give a vertical excitation at $404 \mathrm{~nm}$ (state I), which is about $15 \mathrm{~nm}$ lower than the experimental wavelength, where it involves the same orbitals as in xylene. Theoretical vertical excitation calculations in acetone give $\lambda_{\max }$ of this band at $411 \mathrm{~nm}$ (state I), which shows a fair agreement, implying that the orbitals involved in this transition are $\varphi_{133}$ and $\varphi_{134}$. The experimental second band observed at $316 \mathrm{~nm}$ in xylene, is reproduced theoretically at $311 \mathrm{~nm}$ (state II), where the calculations in xylene indicate that the orbital's $\varphi_{131}$ and $\varphi_{134}$ are involved in this transition. Gas phase calculations give $\lambda_{\max }$ at $311 \mathrm{~nm}$ (state II). Theoretical calculations in acetone show that, this band appears at $308 \mathrm{~nm}$ (state II), which is lower than the experimental wavelength. The third state $(\pi-$ $\left.\pi^{*}\right)^{1,}$ theoretically at $258 \mathrm{~nm}$ in xylene, (state III), where the calculations in xylene indicate that the orbital's $\varphi_{127}$ and $\varphi_{134}$ are involved in this transition. Gas phase calculations give $\lambda_{\max }$ at $258 \mathrm{~nm}$ (state III). Theoretical calculations in acetone show that, this band appears at $253 \mathrm{~nm}$ (state III). The four orbital's $\varphi_{127}, \varphi_{131}, \varphi_{133}$ and $\varphi_{134}$ involved in the theoretical transitions of 3, are shown in "Figure 13". where the first band which involves $\varphi_{133}$ and $\varphi_{134}$, show a CT character, while orbital's $\varphi_{131}$ and $\varphi_{134} \& \varphi_{127}$ and $\varphi_{134}$ involved in the second, and third bands show electron density delocalization and also a CT character. The results of NBO analysis of compound 3 tabulated in Table 6 indicate that there is a strong hyper conjugative interactions $\pi^{*} \mathrm{C}_{9}-\mathrm{C}_{11} \rightarrow \pi^{*} \mathrm{C}_{31}-\mathrm{C}_{33}$, LP (1) $\mathrm{N}_{24} \rightarrow \pi^{*} \mathrm{C}_{1}-\mathrm{C}_{2}$, LP (1) $\mathrm{N}_{6} \rightarrow \pi^{*} \mathrm{C}_{10}-\mathrm{O}_{23}, \pi^{*} \mathrm{C}_{10}-\mathrm{O}_{23} \rightarrow$ $\pi^{*} \mathrm{C}_{9}-\mathrm{C}_{11}, \mathrm{LP}(1) \mathrm{N}_{6} \rightarrow \pi^{*} \mathrm{C}_{4}-\mathrm{C}_{5}$, LP (2) $\mathrm{O}_{54} \rightarrow \sigma^{*} \mathrm{C}_{18}-\mathrm{C}_{20}$ and LP (2) $\mathrm{S}_{8} \rightarrow \pi^{*} \mathrm{C}_{4}-\mathrm{C}_{5}$, for 3 is $58.44,50.97,50.36,47.88$, $33.65,31.04$ and $23.66 \mathrm{kcal} / \mathrm{mol}$, respectively. NBO analysis of the p-OCH3 derivative Table 6 indicates that it retained the extended conjugation of 1 as revealed by the interaction of $\mathrm{C}-\mathrm{N}$ NBOs with those of pyridine ring. Furthermore, the interaction of the oxygen lone orbital's with the $\mathrm{C} 18-\mathrm{C} 20$ $\sigma^{*}$ orbital is marked. The population of the NBO $\mathrm{C} 1-\mathrm{C} 2$, $\mathrm{C} 31-\mathrm{C} 33$, and $\mathrm{C} 10-\mathrm{O} 23$ reflecting a charge transfer away from the thiazolo[3,2-a]pyridine ring.

Table 9. Theoretical and experimental UV spectra of 3, calculated at CAM-B3LYP/6-311G (d,p).

\begin{tabular}{|c|c|c|c|c|c|c|c|c|}
\hline \multirow{3}{*}{ state } & \multicolumn{8}{|l|}{ TD-Theoretical } \\
\hline & \multicolumn{4}{|l|}{ Gas phase } & \multicolumn{4}{|l|}{ Xylene } \\
\hline & Config uration & Coefficient & f & $\lambda, \mathrm{nm}$ & Config uration & Coefficient & f & $\lambda, \mathbf{n m}$ \\
\hline \multirow[t]{2}{*}{ I } & $133-134$ & 0.694 & 0.425 & 404 & $133-134$ & 0.692 & 0.508 & 415 \\
\hline & $130-134$ & 0.407 & 0.193 & 311 & $130-134$ & 0.357 & 0.284 & 311 \\
\hline \multirow{6}{*}{ II } & $131-134$ & 0.473 & & & $131-134$ & 0.504 & & \\
\hline & $131-135$ & 0.145 & & & $131-135$ & 0.175 & & \\
\hline & $133-135$ & 0.222 & & & $133-135$ & 0.223 & & \\
\hline & $127-134$ & 0.313 & 0.286 & 258 & $127-134$ & 0.486 & 0.568 & 258 \\
\hline & $130-135$ & -0.31 & & & $127-135$ & $0.157-$ & & \\
\hline & $130-136$ & 0.109 & & & $129-134$ & 0.285 & & \\
\hline \multirow{5}{*}{ III } & $131-135$ & $0.21-$ & & & $132-136$ & 0.177 & & \\
\hline & $132-134$ & 0.191 & & & $133-136$ & $0.113-$ & & \\
\hline & $132-135$ & -0.21 & & & $133-137$ & 0.25 & & \\
\hline & $132-136$ & 0.321 & & & & & & \\
\hline & $133-136$ & -0.11 & & & & & & \\
\hline
\end{tabular}

Table 9. Continue.

\begin{tabular}{|c|c|c|c|c|c|c|}
\hline \multirow{3}{*}{ state } & \multicolumn{4}{|l|}{ TD-Theoretical } & \multicolumn{2}{|c|}{ Experimental } \\
\hline & \multicolumn{4}{|l|}{ Acetone } & \multirow{2}{*}{$\begin{array}{l}\text { Acetone } \\
\lambda, \mathrm{nm}\end{array}$} & \multirow{2}{*}{$\begin{array}{l}\text { Xylene } \\
\lambda_{\text {gnm }}\end{array}$} \\
\hline & Configuration & Coefficient & f & $\lambda, \mathrm{nm}$ & & \\
\hline I & $133-134$ & 0.692 & 0.480 & 411 & 416 & 419 \\
\hline \multirow{4}{*}{ II } & $130-134$ & 0.358 & 0.301 & 308 & \multirow{4}{*}{313} & \multirow{4}{*}{316} \\
\hline & $131-134$ & 0.520 & & & & \\
\hline & $131-135$ & 0.179 & & & & \\
\hline & $133-135$ & 0.162 & & & & \\
\hline \multirow{5}{*}{ III } & $127-134$ & -0.261 & 0.534 & 253 & & \\
\hline & $129-134$ & 0.372 & & & & \\
\hline & $130-139$ & 0.157 & & & & \\
\hline & $131-139$ & 0.139 & & & & \\
\hline & $133-137$ & 0.41 & & & & \\
\hline
\end{tabular}




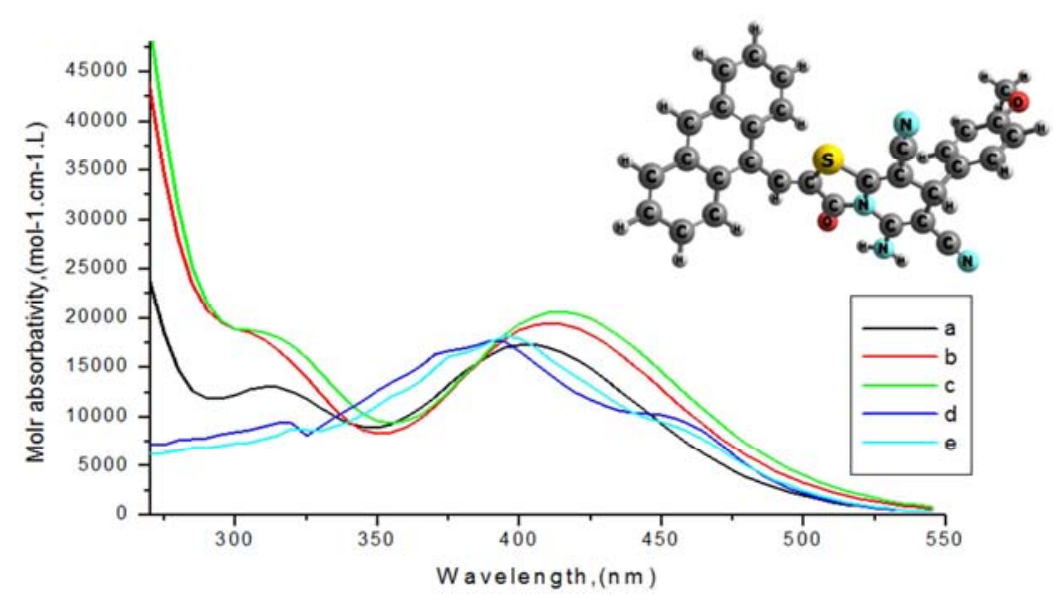

Figure 15. Electronic absorption spectra of 3, (a) theoretical in gas phase, (b) theoretical in acetone, (c) theoretical in xylene, (d) experimental in acetone, (e) experimental in xylene.

\subsubsection{Electronic Absorption Spectra of Compound 4}

Compound 4 results by inserting $\mathrm{Cl}$-atom in position $\mathrm{X}$ in $\mathrm{Ph}$ $\mathrm{X}$ of compound 1 . The experimental and theoretical electronic absorption spectra of compound 4 in xylene and acetone are shown in "Figure 16", and Table 10. The experimental spectrum in xylene is composed of two bands at $420 \mathrm{~nm}$, and $314 \mathrm{~nm}$. The change of solvent polarity from xylene to acetone results in a small red shift by $3 \mathrm{~nm}$ of the first band, and the second band red shift by $4 \mathrm{~nm}$. Additionally, increasing solvent polarity causes a marked decrease in the intensity of both bands. The values of molar absorptive $(\varepsilon=45000)$ indicates that the two observed bands have $\pi-\pi^{*}$ character. The theoretical vertical transitions using CAM / B3LYP/6-311G (d, p) level is valuable for the analysis of the experimental UV Spectra of 4 in xylene and acetone, which gives values for $\lambda_{\max }$ of $419 \mathrm{~nm}$ (state I) for the first band, $311 \mathrm{~nm}$ (state II) for the second band, and $258 \mathrm{~nm}$ (state III) for the third band as shown in Table 10. The theoretical transition of the first band in xylene involves orbital's $\varphi_{133}$ and $\varphi_{134}$, showing a good agreement between the observed and the calculated wavelengths. Theoretical transitions in the gas phase give a vertical excitation at $407 \mathrm{~nm}$ (state I), which is about $13 \mathrm{~nm}$ lower than the experimental wavelength, where it involves the same orbitals as in xylene. Theoretical vertical excitation calculations in acetone give $\lambda_{\max }$ of this band at 415 $\mathrm{nm}$ (state I), which shows a fair agreement, implying that the orbitals involved in this transition are $\varphi_{133}$ and $\varphi_{134}$. The experimental second band observed at $314 \mathrm{~nm}$ in xylene, is reproduced theoretically at $311 \mathrm{~nm}$ (state II), where the calculations in xylene indicate that the orbital's $\varphi_{131}$ and $\varphi_{134}$ are involved in this transition. Gas phase calculations give $\lambda_{\max }$ at
$311 \mathrm{~nm}$ (state II). Theoretical calculations in acetone show that, this band appears at $308 \mathrm{~nm}$ (state II), which is lower than the experimental wavelength. Theoretical gas phase wavelength is found to be lower than the observed wavelength in acetone. The third state $\left(\pi-\pi^{*}\right)^{1}$, which theoretically at $258 \mathrm{~nm}$ in xylene, (state III), where the calculations in xylene indicate that the orbital's $\varphi_{131}$ and $\varphi_{135}$ are involved in this transition. Gas phase calculations give $\lambda_{\max }$ at $253 \mathrm{~nm}$ (state III). Theoretical calculations in acetone show that, this band appears at $254 \mathrm{~nm}$ (state III). It shows that the orbitals involved in the transition are $\varphi_{133}$ and $\varphi_{137}$. The five orbital's $\varphi_{131}, \varphi_{133}, \varphi_{134}, \varphi_{135}$ and $\varphi_{137}$ involved in the theoretical transitions of 4 , are shown in "Figure 13 ", where the first band which involves $\varphi_{133}$ and $\varphi_{134}$, show a CT character, while orbital's $\varphi_{131}$ and $\varphi_{135} \& \varphi_{131}$ and $\varphi_{134} \& \varphi_{133}$ and $\varphi_{137}$ involved in the second and third bands show electron density delocalization and also CT character. The results of NBO analysis of compound 4 tabulated in Table 6 indicate that there is a strong hyper conjugative interactions $\pi^{*} \mathrm{C}_{16}-\mathrm{C}_{19} \rightarrow$ $\pi * \mathrm{C}_{15}-\mathrm{C}_{18}, \pi * \mathrm{C}_{9}-\mathrm{C}_{11} \rightarrow \pi * \mathrm{C}_{30}-\mathrm{C}_{32}, \mathrm{LP}$ (1) $\mathrm{N}_{23} \rightarrow \pi * \mathrm{C}_{1}-\mathrm{C}_{2}, \mathrm{LP}$ (1) $\mathrm{N}_{6} \rightarrow \pi^{*} \mathrm{C}_{10}-\mathrm{O}_{22}, \pi^{*} \mathrm{C}_{10}-\mathrm{O}_{22} \rightarrow \pi^{*} \mathrm{C}_{9}-\mathrm{C}_{11}, \mathrm{LP}(1) \mathrm{N}_{6} \rightarrow \pi * \mathrm{C}_{4}-\mathrm{C}_{5}$ and LP (2) $\mathrm{S}_{8} \rightarrow \pi^{*} \mathrm{C}_{4}-\mathrm{C}_{5}$, for 4 is $249.52,56.71,52.68,49.64$, $47.19,34.25$, and $24.15 \mathrm{kcal} / \mathrm{mol}$, respectively. NBO analysis of the $\mathrm{p}-\mathrm{Cl}$ derivative Table 6 indicates that it retained the extended conjugation of 1 as revealed by the interaction of $\mathrm{C}-\mathrm{Cl}$ NBOs with those of phenyl ring. Furthermore, the interaction of the cholor lone orbital's with the $\mathrm{C} 30-\mathrm{C} 32 \sigma^{*}$ orbital is marked. The population of the NBO C15-C18, C10-O22, C13-C14, C1-C2, $\mathrm{C} 16-\mathrm{C} 19$, and $\mathrm{C} 30-\mathrm{C} 32$ reflecting a charge transfer away from the thiazolo[3,2-a]pyridine ring.

Table 10. Theoretical and experimental UV spectra of 4, calculated at CAM-B3LYP/6-311G (d,p).

\begin{tabular}{|c|c|c|c|c|c|c|c|c|}
\hline \multirow{3}{*}{ state } & \multicolumn{8}{|l|}{ TD-Theoretical } \\
\hline & \multicolumn{4}{|l|}{ Gas phase } & \multicolumn{4}{|l|}{ Xylene } \\
\hline & Config uration & Coefficient & f & $\lambda, \mathbf{n m}$ & Config uration & Coefficient & $\mathbf{f}$ & $\lambda, \mathbf{n m}$ \\
\hline \multirow[t]{3}{*}{ I } & $133-134$ & 0.694 & 0.420 & 407 & $133-134$ & 0.692 & 0.509 & 419 \\
\hline & $131-134$ & -0.24 & 0.165 & 311 & $129-134$ & 0.120 & 0.323 & 311 \\
\hline & $132-134$ & 0.569 & & & $131-134$ & 0.468 & & \\
\hline \multirow[t]{2}{*}{ II } & $132-135$ & 0.267 & & & $132-134$ & $0.406-$ & & \\
\hline & $133-135$ & 0.150 & & & $132-135$ & $0.176-$ & & \\
\hline
\end{tabular}




\begin{tabular}{|c|c|c|c|c|c|c|c|c|}
\hline \multirow{3}{*}{ state } & \multicolumn{8}{|l|}{ TD-Theoretical } \\
\hline & \multicolumn{4}{|l|}{ Gas phase } & \multicolumn{4}{|l|}{ Xylene } \\
\hline & Config uration & Coefficient & $f$ & $\lambda, \mathbf{n m}$ & Config uration & Coefficient & f & $\lambda, \mathrm{nm}$ \\
\hline \multirow{9}{*}{ III } & $126-135$ & $0.10-$ & 0.521 & 253 & $130-134$ & 0.227 & 0.869 & 258 \\
\hline & $127-134$ & 0.144 & & & $131-135$ & 0.335 & & \\
\hline & $129-134$ & -0.160 & & & $131-136$ & -0.287 & & \\
\hline & $130-135$ & 0.132 & & & $132-136$ & $0.252-$ & & \\
\hline & $131-135$ & 0.415 & & & $133-136$ & 0.268 & & \\
\hline & $131-136$ & -0.250 & & & $133-137$ & 0.229 & & \\
\hline & $132-136$ & $0.25-$ & & & & & & \\
\hline & $133-136$ & $0.21-$ & & & & & & \\
\hline & $133-137$ & 0.126 & & & & & & \\
\hline
\end{tabular}

Table 10. Continued.

\begin{tabular}{|c|c|c|c|c|c|c|}
\hline \multirow{3}{*}{ state } & \multicolumn{4}{|l|}{ TD-Theoretical } & \multicolumn{2}{|c|}{ Experimental } \\
\hline & \multicolumn{4}{|l|}{ Acetone } & \multirow{2}{*}{$\begin{array}{l}\text { Acetone } \\
\lambda \lambda, \mathrm{nm}\end{array}$} & \multirow{2}{*}{$\begin{array}{l}\text { Xylene } \\
\lambda, \text { nm }\end{array}$} \\
\hline & Configuration & Coefficient & f & $\lambda, \mathrm{nm}$ & & \\
\hline \multirow[t]{3}{*}{ I } & $133-134$ & 0.692 & 0.483 & 415 & 423 & 420 \\
\hline & $129-134$ & 0.103 & 0.312 & 308 & & \\
\hline & $131-134$ & 0.485 & & & & \\
\hline \multirow{6}{*}{ II } & $131-135$ & 0.103 & & & 318 & 214 \\
\hline & $132-134$ & -0.389 & & & 318 & 314 \\
\hline & $132-135$ & -0.188 & & & & \\
\hline & $133-135$ & -0.133 & & & & \\
\hline & $128-134$ & $0.256-$ & 0.539 & 254 & & \\
\hline & $130-134$ & 0.383 & & & & \\
\hline \multirow{4}{*}{ III } & $130-135$ & 0.112 & & & & \\
\hline & $131-140$ & $0.167-$ & & & & \\
\hline & $133-136$ & -0.138 & & & & \\
\hline & $133-137$ & 0.414 & & & & \\
\hline
\end{tabular}

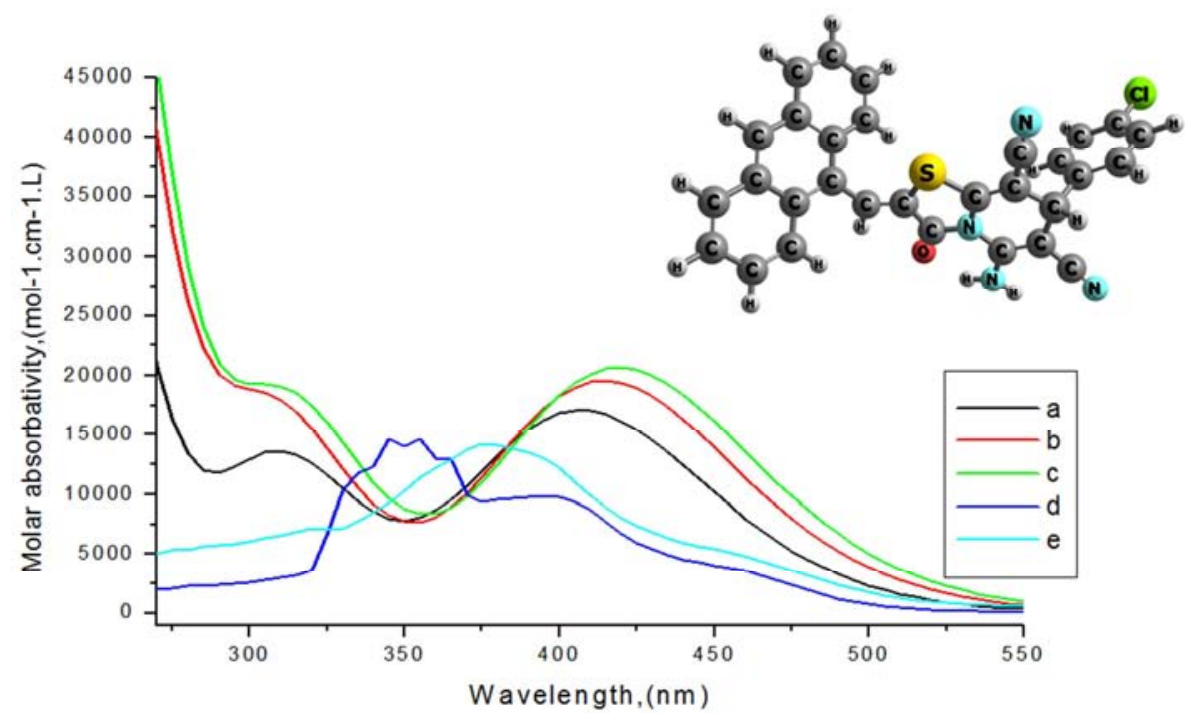

Figure 16. Electronic absorption spectra of 4, (a) theoretical in gas phase, (b) theoretical in acetone, (c) theoretical in xylene, (d) experimental in acetone, (e) experimental in xylene.

\subsection{Summary and Conclusion}

The optimized electronic structure of 5-amino-2-(anthracen-9ylmethylene)-3-oxo-7-phenyl-2,3-dihydro-7H-thiazolo[3,2-

a]pyridine-6,8-dicarbonitrile, compound 1 and its derivatives, 2 4, are investigated theoretically at B3LYP/6-311G (d, p). All the studied compounds are found to be non-planar. The dihedral angles results show that the phenyl at $\mathrm{C}_{3}$ and the anthranyl at $\mathrm{C}_{9}$ are out of the molecular plane of thiazolo[3,2-a]pyridines by $111^{\circ}$ and $128^{\circ}$ respectively, resulting in a significant impact on the electronic and structural properties of compounds 1-4. The ground state properties of 1 and its derivatives show that compound 4 has the lowest $\mathrm{E}_{\mathrm{HOMO}}, \mathrm{E}_{\mathrm{LUMO}}$, and Egap indicating highest reactivity. From the computed dipole moment, compound 3 is found to have the highest polarity. The HOMOLUMO energy gap helped in analyzing the chemical reactivity, hardness, softness, chemical potential and electro negativity. The natural charge distribution of the compounds 1-4 were studied. The non-linear optical indicating from the values of calculated dipole moment and first order hyperpolarizability. 
The total electron density surface with MEP confirmed the different negative and positive potential sites of the molecule. Electronic absorption spectra are investigated experimentally in non-polar solvent (xylene) and polar solvent (acetone); and theoretically in gas phase, xylene and acetone using CAMB3LYP/6-311G $(d, p)$. The band maxima $\left(\lambda_{\max }\right)$ and intensities of the spectra are found to have solvent dependence. The bands of compounds 1, 2, and 3 show blue shift, while compounds 4 show red shift. Theoretical calculations of the vertical excitations at the CAM-B3LYP/6-311G $(\mathrm{d}, \mathrm{p})$ reproduce the experimental spectra, indicating a good agreement between theory and experiment. The NBO analysis of the compounds 14 indicated the intermolecular charge transfer between the bonding and antibonding orbital's.

\section{References}

[1] Hari Datta Khanal and Yong Rok Lee, (2015) Organocatalyzed oxidative $\mathrm{N}$-annulation for diverse and polyfunctionalized pyridines. Chem. Commun. 51: 94679470. doi: 10.1039/c5cc01807b.

[2] Yepes AF, Jaimes E, Bahsas A, Palma A, Hursthouse MB, Cobo J, Glidewell C. (2010) Ring conformations and intermolecular interactions in two fused dibenzoazocines. Acta Crystallographica. Section C, Crystal Structure Communications. 66 : 284-288. doi: $10.1107 / \mathrm{S} 0108270110014708$.

[3] Suksrichavalit T., Prachayasittikul S., Nantasenamat C., Isarankura-Na-Ayudhya V., Prachayasittikul C., (2009) Copper complexes of pyridine derivatives with superoxide scavenging and antimicrobial activities. Eur. J. Med. Chem. 44: 3259-3265. doi: 10.1016/j.ejmech.2009.03.033

[4] Mohamed Ibrahim H., Haider Behbehani, (2014) Synthesis of A New Class of Pyridazin-3-one and 2-Amino-5arylazopyridine Derivatives and Their Utility in the Synthesis of Fused Azines. Mol. 19: 2637-2654. doi: 10.3390/molecules 19022637 .

[5] Roxana M. Butnariu, Maria D. Caprosu, Vasilichia Bejan, Ionel I. Mangalagiu, Margareta Ungureanu, Antonia Poiata, Cristina Tuchilus, Margareta Florescu, (2009) Pyridazine and phthalazine derivatives with potential antimicrobial activity. J. Hetero. Chem. 44: 1149-1152. https://doi.org/10.1002/jhet.5570440528

[6] Roberta Barbaro, Laura Betti, Maurizio Botta, Federico Corelli, Gino Giannaccini, Laura Maccari, Fabrizio Manetti, Giovannella Strappaghetti, and Stefano Corsano, (2001) Synthesis, Biological Evaluation, and Pharmacophore Generation of New Pyridazinone Derivatives with Affinity toward $\alpha 1-$ and $\alpha 2$-Adrenoceptors. J. Med. Chem. 44: 21182132. doi: 10.1021/jm010821u.

[7] Tracy E, Zhu M, Streiff C, Sahn DJ, Ashraf M. (2018) Quantification of the area and shunt volume of multiple, circular, and noncircular ventricular septal defects: A 2D/3D echocardiography comparison and real time 3D color Doppler feasibility determination study. Echocardiography. 35: 90-99. doi: 10.1111/echo.13742.

[8] Nermin A. Marzouk, Ahmed H. Shamroukh, Abeer H. AlSaadny, J. A. Micky and Farouk, M. E. Abd El-Megeid,
(2011) Synthesis, Isomerization, and Antimicrobial Evaluation of Some IndenothienoPyrimidine Derivatives. J. Amer. Sci. 7: 362-369.

[9] Houda Serrar, et al, (2018) Two derivatives of 7-aminothiazolo[3,2-a]pyrimidine as inhibitors of mild steel corrosion in $1.0 \mathrm{M} \mathrm{HCl}$ solution: part I synthesis of inhibitors and electrochemical study. J. Chem. Tech. Meta. 53: 324-335.

[10] Mohamoud N. A., (2015) Synthesis of some new thiazolo, pyrano and pyrimidinone derivatives of expected biological activities. Int. J. Adv. Res. 3: 977-987.

[11] Hany J. Al-Majjar, Assem Barakar, Abdullah M. Al-Majid, Yahia, N. Mabkhot, Manuel Weber, Hazem, A. Ghabbour, Hoongkun Fun, (2014) A Greener, Efficient Approach to Michael Addition of Barbituric Acid to Nitroalkene in Aqueous Diethylamine Medium. Mol. 19: 1150-1162. doi:10.3390/molecules19011150

[12] Affram K. et al, (2015) In Vitro and in Vivo Antitumor Activity of Gemcitabine Loaded Thermosensitive Liposomal Nanoparticles and Mild Hyperthermia in Pancreatic Cancer. Int. J. Adv. Res. 3: 859-874.

[13] Teuber L., (1990) Naturally Occurring 1,2-Dithiolanes and 1,2,3-Trithianes. Chemical and Biological Properties. J. Sulfur Reports. 9: 257-333. https://oi.org/10.1080/01961779008048732

[14] Minotti Menna P G, Salvatorelli E, Cairo G, Gianni L., (2004) LAnthracyclines: molecular advances and pharmacologic developments in antitumor activity and cardiotoxicity. Pharmacol Rev. 56: 185-229. doi: 10.1124/pr.56.2.6

[15] Kanda N. et al., (1971) A new antitumor antibiotic, kidamycin. I. Isolation, purification and properties of kidamycin. J. Antibiotics, 24: 599-606. http://doi.org/10.7164/antibiotics.24.599

[16] Degtev MI., Dudukalov NV., (2012) Synthesis of new derivatives of 2-acylisothiocyanate of 1-nitro-9,10anthraquinone with antimicrobial activity basic research, 3: 167-172.

[17] Sendel E., - S (1964) Catalog of Copyright Entries: Third series. 172 .

[18] Ayres G. H., (1949), Evaluation of Accuracy in Photometric Analysis. Anal. Chem. 21: 652-657. doi: 10.1021/ac60030a002

[19] Denisov Popov VY, (2008) Synthesis of new cationic monomers based on $\omega$-bromocarboxylic acids CIO. Proceedings of the Conference "Modern high technologies" 4- C. 138.

[20] Murata N, Allakhverdiev S. I, Nishiyama Y, (2012) The mechanism of photoinhibition in vivo: Re-evaluation of the roles of catalase, $\alpha$-tocopherol, non-photochemical quenching, and electron transport. Biochimica et Biophysica Acta (BBA)Bioenergetics. 1817: 1127-1133. https://doi.org/10.1016/j.bbabio.2012.02.020

[21] Zvarych V. I., Musyanovych R. Ya., Chervetsova V. G., Komarovska-Porokhnyavets O. Z., Stasevych M. V., Novikov V. P., (2013) Synthesis of new derivatives of 2acylisothiocyanate of 1-nitro-9, 10-anthraquinone with antimicrobial activity. Academic Journals and Conferenes of Lviv Polytechnic National University. SCHMT 761. 
[22] Abdel Halim S, Ali Kh. Khalil (2017) TD-DFT calculations, NBO analysis and electronic absorption spectra of some thiazolo[3,2-a]pyridine derivatives. J. Mol. Struct. 1147: 651667. http://dx.doi.org/10.1016/j.molstruc.2017.06.098.

[23] Abdel Halim S, Ibrahim MA (2017) Synthesis, DFT calculations, electronic structure, electronic absorption spectra, natural bond orbital (NBO) and nonlinear optical (NLO) analysis of the novel 5-methyl-8H-benzo[h]chromeno[2,3-b][1,6]naphthyridine-

6(5H),8-dione (MBCND). J. Mol. Struct. 1130: 543-558. http://dx.doi.org/10.1016/j.molstruc.2016.10.058.

[24] Abdel Halim S, Laila I. Ali, Sameh Gamal Sanad (2017) Theoretical calculations of solvation 12-Crown-4 (12CN4) in aqueous solution and its experimental interaction with nano CuSO4. Int. J. Nano Dimens., 8: 142-158. DOI: 10.22034/ijnd.2017.24995.

[25] Becke AD (1993) A new mixing of Hartree-Fock and local density-functional theories. J. Chem. Phys. 98: 1372-1376. doi: 10.1063/1.464304. Becke AD (1993) Densityfunctional thermochemistry, III: The role of exact exchange. J. Chem. Phys. 98: 5648-5652. doi: 10.1063/1.464913

[26] Lee C, Yang W, Parr RG (1988) Development of the ColleSalvetti correlation-energy formula into a functional of the electron density, Phys. Rev. B Condens. Matter. 37: 785-789. doi:10.1103/PhysRevB.37.78.

[27] Stefanov B, B. G. Liu, A. Liashenko, P. Piskorz, I. Komaromi, R. L. Martin, D. J. Fox, T. Keith, M. A. Al-Laham, C. Y. Peng, A. Nanayakkara, M. Challacombe, P. M. W. Gill, B. Johnson, W. Chen, M. W. Wong, C. Gonzalez, J. A. Pople, Gaussian, Inc., Pittsburgh PA. (2003).

[28] Frisch M, J. G. W. Trucks, H. B. Schlegel, G, E. Scuseria, et al., Gaussian, Inc., Wallingford CT, (2009).

[29] GaussView, Version 5, Dennington, R.; Keith, T.; Millam, J. Semichem Inc., Shawnee Mission KS, (2009).

[30] http://www.chemcraftprog.com.

[31] Avci D (2011) Second and third-order nonlinear optical properties and molecular parameters of azo chromophores: semiempirical analysis. Spectrochim. Acta A. 82: 37-43. doi: 10.1016/j.saa.2011.06.037

[32] Avci D, Başoğlu A, Atalay Y (2013) NLO and NBO Analysis of Sarcosine Maleic Acid by Using HF and B3LYP Calculations, Hindawi Publishing Corporation J. Chem. Article ID 712130: 1-16. doi: 10.1155/2013/712130

[33] Tomasz S, Katarzyna S, Benoît C (2014): Ab initio HartreeFock calculations on linear and second-order nonlinear optical properties of ionic organic crystals, J. Chem. Phys. 141: 104109. doi: 10.1063/1.4894483

[34] Jean-Luc Adam, (2002) Lanthanides in Non-Oxide Glasses. Chem. Rev. 102: 2461-2476. doi: 10.1021/cr010305b

[35] Yanai T, Tew D, and Handy N, (2004) A new hybrid exchange-correlation functional using the Coulombattenuating method (CAM-B3LYP). Chem. Phys. Lett. 393: 51-57. doi: https://doi.org/10.1016/j.cplett.2004.06.011

[36] Chocholoušová J, Špirko V, Hobza P, (2004) First local minimum of the formic acid dimer exhibits simultaneously red-shifted $\mathrm{O}-\mathrm{H} . . \mathrm{O}$ and improper blue-shifted $\mathrm{C}-\mathrm{H} . . \mathrm{O}$ hydrogen bonds. Phys. Chem. Chem. Phys. 6: 37-41. doi: 10.1039/B314148A
[37] Szafran M., Komasa A., Bartoszak-Adamska E., (2007) Crystal and molecular structure of 4-carboxypiperidinium chloride (4-piperidinecarboxylic acid hydrochloride). J. Mol. Struct. 827:101-107. doi: 10.1016/j.molstruc.2006.05.012

[38] Gamal A. El-Hiti, Keith Smith, Amany S. Hegazy, Ali M. Masmali and Benson M. Kariuki, (2014) Crystal structure of 2-tert-butyl-1,3-thiazolo[4,5-b]pyridine. Acta Cryst. E70: 932937. doi:10.1107/S160053681401633X

[39] Gamal A. El-Hiti, Keith Smith, Amany S. Hegazy, Saud A. Alanazi and Benson M. Kariuki, (2015) Crystal structure of 2(2-methylphenyl)-1,3-thiazolo[4,5-b]pyridine. Acta Cryst. E71: 562-563. doi: 10.1107/S2056989015012797

[40] Gamal A. El-Hiti, Keith Smith, Amany S. Hegazy, Mansour D. Ajarim, Benson M. Kariuki (2015) Crystal structure of 2(3-nitrophenyl)-1,3-thiazolo[4,5-b]pyridine. Acta. Cryst. E71: 0877-882. doi: 10.1107/S2056989015019118

[41] Reddy C, Rao D, Yakub V, Nagaraj A (2010) Synthesis and in vitro Study of Some New Bis(thiadiazolyl-2H-pyrazolo[3,4d] [1,3]thiazole)- methanes as Potential Nematicides, Acta Chim. Slov. 57: 798-807. doi: acta-arhiv.chem-soc.si/57/57-4798.pdf

[42] Natorajan S, Shanmugam G, and MartinCryst SA, (2008) Res. Technal. 43: 561; Chemia D. S, Zysss J (1987) Nonlinear Optical Properties of Organic Molecules and Crystals Academic Press, Orlando, FL, Bradshow D. S, Andrews D. L (2009) J. Nonlinear Opt. Phys. Matter 18: 285. Sures S (2013) The Growth and the Optical, Mechanical, Dielectric and Photoconductivity Properties of a New Nonlinear Optical Crystal-L-Phenylalanine-4-nitrophenol NLO Single Crystal Scientific-Research An Academic Publisher1, 3: 87-91 doi: 10.4236/jcpt.2013.33014

[43] Cheng LT, Tam W, Stevenson SH, Meredith GR, Rikken G, Marder SR (1991) Electric field induced second harmonic generation with and without fringes, J. Phys. Chem. 95: 10631. doi: https://doi.org/JPCHAX

[44] Kaatz P, Donley EA, Shelton DP (1998) Analysis of nonlinear optical properties in donor-acceptor materials, J. Chem. Phys. 108: 849. doi: https://doi.org/10.1063/1.475448, Citation, CAS.

[45] Gnanasambandan T, Gunasekaran S, Seshadri S (2014) Experimental and theoretical study of p-nitroacetanilide. Spectrochimica. Acta Part A: Molecular and Biomolecular Spectroscopy 117: 557-567. https://doi.org/10.1016/j.saa.2013.08.061

[46] Murray JS, Sen K (1996) Molecular Electrostatic Potentials, Conseptsana Applications, Elsevier, Amsterdam 7 and Sscrocco E, Tomasi J, (1978) Electronic Molecular Structure, Reactivity and Intermolecular Forces: An Euristic Interpretation by Means of Electrostatic Molecular Potentials, Adv. Quant. Chem. 11: 115-193. doi: https://doi.org/10.1016/S0065-3276(08)60236-1

[47] Politzer P, Murray JS (2002) The fundamental nature and role of the electrostatic potential in atoms and molecules. Theor. Chem. Acc. 108: 134-142. doi:10.1007/s00214-002-0363-9

[48] Sajan D, Joseph L, Vijayan N, Karabacak M (2011) Natural bond orbital analysis, electronic structure, non-linear properties and vibrational spectral analysis of 1-histidinium bromide monohydrate: A density functional theory Spectrochim. Acta A. 81: 85-98. doi: 10.1016/j.saa.2011.05.052 